\title{
Role of Advection of Parameterized Turbulence Kinetic Energy in Idealized Tropical Cyclone Simulations
}

\author{
XiAOMIN CHEN $^{\mathrm{a}}$ AND GeORGE H. BRyan ${ }^{\mathrm{b}}$ \\ ${ }^{\mathrm{a}}$ NOAA/AOML/Hurricane Research Division, Miami, Florida \\ ${ }^{\mathrm{b}}$ National Center for Atmospheric Research, Boulder, Colorado
}

(Manuscript received 22 March 2021, in final form 22 July 2021)

\begin{abstract}
Horizontal homogeneity is typically assumed in the design of planetary boundary layer (PBL) parameterizations in weather prediction models. Consistent with this assumption, PBL schemes with predictive equations for subgrid turbulence kinetic energy (TKE) typically neglect advection of TKE. However, tropical cyclone (TC) boundary layers are inhomogeneous, particularly in the eyewall. To gain further insight, this study examines the effect of advection of TKE using the Mellor-Yamada-Nakanishi-Niino (MYNN) PBL scheme in idealized TC simulations. The analysis focuses on two simulations, one that includes TKE advection (CTL) and one that does not (NoADV). Results show that relatively large TKE in the eyewall above $2 \mathrm{~km}$ is predominantly attributable to vertical advection of TKE in CTL. Interestingly, buoyancy production of TKE is negative in this region in both simulations; thus, buoyancy effects cannot explain observed columns of TKE in TC eyewalls. Both horizontal and vertical advection of TKE tends to reduce TKE and vertical viscosity in the nearsurface inflow layer, particularly in the eyewall of TCs. Results also show that the simulated TC in CTL has slightly stronger maximum winds, slightly smaller radius of maximum wind, and $\sim 5 \%$ smaller radius of gale-force wind than in NoADV. These differences are consistent with absolute angular momentum being advected to smaller radii in CTL. Sensitivity simulations further reveal that the differences between CTL and NoADV are more attributable to vertical advection (rather than horizontal advection) of TKE. Recommendations for improvements of PBL schemes that use predictive equations for TKE are also discussed.
\end{abstract}

KEYWORDS: Boundary layer; Tropical cyclones; Hurricanes/typhoons; Numerical weather prediction/forecasting; Mesoscale models; Subgrid-scale processes

\section{Introduction}

Boundary layer turbulent processes play an important role in regulating tropical cyclone (TC) intensity and structure changes (e.g., Braun and Tao 2000; Foster 2009; Nolan et al. 2009; Smith and Thomsen 2010; Bryan 2012; Rotunno and Bryan 2012; Gopalakrishnan et al. 2013; Zhang et al. 2015; Bu et al. 2017; Chen et al. 2021b). An important metric of turbulence intensity is turbulence kinetic energy (TKE), which can be related to the transport of momentum, heat, and moisture, as well as kinetic-energy dissipation rate in the boundary layer (Stull 1988). In numerical forecast models, high-order planetary boundary layer (PBL) parameterizations based on the formulation of Mellor and Yamada (1982) have predictive equations for TKE and can diagnose other turbulence quantities based partly on TKE. Understanding the TKE distribution in hurricanes is a key to the evaluation of these PBL schemes, which can further provide valuable insights/guidance toward improving TC intensity and structure forecasts.

The direct in situ observations of TKE in TC boundary layers by manned aircrafts are scarce (e.g., Zhang et al. 2011), in part due to the safety and practical considerations. The usage of small unmanned aircraft systems (sUAS) in recent years adds additional TKE observations in hurricane boundary layers (e.g., Cione et al. 2020). Nevertheless, a more complete view of the distribution of TKE in hurricanes was derived using airborne

Corresponding author: Xiaomin Chen, xiaomin.chen@noaa.gov
Doppler radars (Lorsolo et al. 2010); high TKE $\left(>4 \mathrm{~m}^{2} \mathrm{~s}^{-2}\right.$ ) was found in the boundary layer (roughly $z<1 \mathrm{~km}$ ) and within the eyewall, and TKE was lower $\left(<2 \mathrm{~m}^{2} \mathrm{~s}^{-2}\right)$ above the PBL and outside the eyewall (Fig. 1).

While both observations (e.g., Zhang et al. 2011; Ming et al. 2014) and large-eddy simulations (LESs; Zhu 2008; Bryan et al. 2017) indicate that turbulence in the TC boundary layer is predominantly shear driven, the relative importance of all TKE budget terms within the eyewall remains unclear. Kepert (2012) hypothesized that the high TKE within the eyewall is predominantly attributed to local buoyancy production. In comparison, Smith and Thomsen (2010) suggested that the high TKE in the eyewall is attributed to the upward TKE advection by eyewall updrafts. Importance of TKE advection was also discussed by Nolan et al. (2009); they found excessive downward mixing of angular momentum near and outside of the radius of maximum winds (RMW) when using the MellorYamada-Janjić (MYJ) PBL scheme, and further hypothesized that this could be attributed to the neglect of advection of subgrid TKE. PBL schemes for numerical weather prediction (NWP) models typically adopt a simplified version of the subgrid TKE budget equation, assuming horizontal homogeneity and negligible vertical advection for subgrid-scale processes (e.g., Stull 1988, p. 152; Kosović et al. 2020). The subgrid TKE advection terms are thereby omitted under these assumptions. However, these assumptions are clearly invalid in the TC boundary layer where flows are inhomogeneous, and also invalid in the eyewall region where nonhydrostatic processes can be substantial and strong updrafts exist. For example, in a 


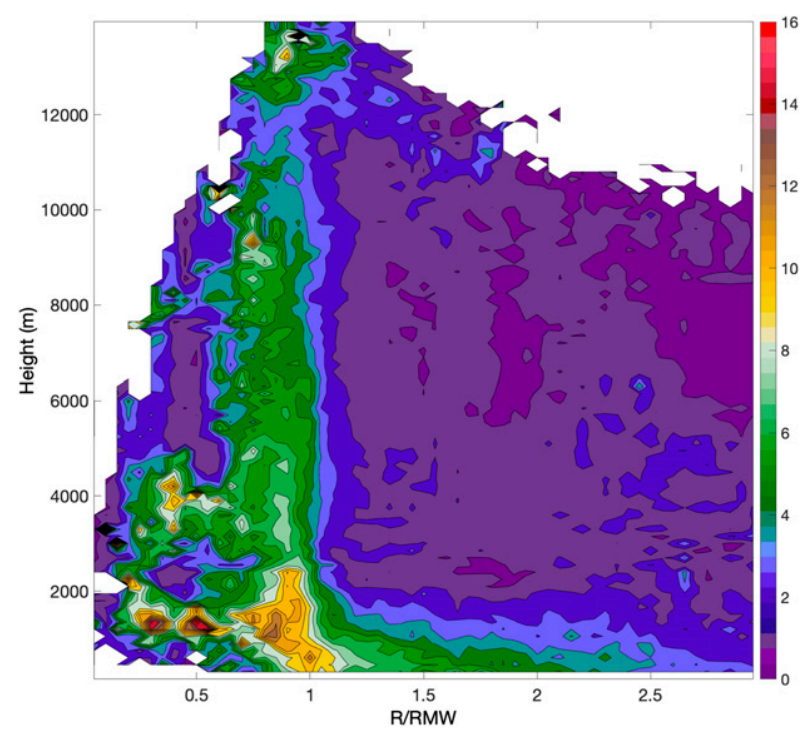

FIG. 1. Composite TKE $\left(\mathrm{m}^{2} \mathrm{~s}^{-2}\right)$ derived from airborne radar data from 20 radial legs of NOAA P3 flights in the 2003-10 hurricane seasons as a function of height and the radius $(R)$ normalized by the radius of maximum winds (RMW). Adapted from Lorsolo et al. (2010).

Weather Research and Forecasting (WRF) Model LES of landfalling Hurricane Ivan (2004), Zhu (2008) found that the large negative TKE advection nearly balances the shear production in the middle to upper boundary layer at a radius of $\sim 80 \mathrm{~km}$.

Previous PBL evaluation studies recommend high-order PBL schemes for TC modeling, given their capability to capture the logarithmic wind profile in the boundary layer (Kepert 2012) and to reproduce the inflow structures and turbulence properties under different thermodynamic conditions (Chen et al. 2021a; X. Chen et al. 2021, unpublished manuscript). However, the impact of subgrid TKE advection on the simulation of boundary layer structure as well as TC intensity/structure changes should be examined, in part due to the typical omission of subgrid TKE advection in NWP models. One exception is the Mellor-Yamada-NakanishiNiino (MYNN) PBL scheme which has an option to include advection of subgrid TKE; however, the advection of subgrid TKE was known to cause numerical instability near the lateral boundaries and thereby has not been activated by default in operational models including NOAA's High-Resolution Rapid Refresh (HRRR) and Rapid Refresh (RAP) (Olson et al. 2019). In the numerical model used for this study, the MYNN scheme and the option of advection of subgrid TKE are available, and we perform numerical simulations to explore this issue. Specifically, the following questions will be addressed in this study: 1) What is the impact of advection of subgrid TKE on the boundary layer structure in idealized TCs? 2) What mechanisms are responsible for the high TKE aloft observed in the eyewall? 3) Does the advection of subgrid TKE affect the TC structure and intensity change and, if so, what are the driving factors?
The remainder of the paper is organized as follows. Section 2 provides an overview of the MYNN scheme and modifications made for this study to improve wind profiles in hurricane conditions. Experiment design and model setup are presented in section 3. In section 4, a comparison of the experiments with and without advection of subgrid TKE is presented, and differences in the TC intensity/size, turbulence properties, and inflow structures between these experiments are discussed. The physical mechanisms responsible for the high TKE aloft within the eyewall are discussed, and suggestions to further improve simulations of TCs when using PBL schemes that have predictive equations for subgrid TKE are provided in section 5 . Concluding remarks are presented in section 6 .

\section{Overview of the MYNN scheme and additional improvement}

The MYNN scheme (Nakanishi and Niino 2004, 2009) is a popular, high-order closure PBL scheme that has been integrated into operational and research models, including the Advanced Research version of the WRF (WRF-ARW; Skamarock et al. 2008) and NOAA's latest Unified Forecast System (UFS; Harris et al. 2020). MYNN predicts subgrid $\mathrm{TKE}^{1}$ and parameterizes other turbulence quantities based partly on TKE. For example, the vertical eddy viscosity $K_{m}$ in MYNN is

$$
K_{m}=L q S_{m},
$$

where $L$ is the so-called master mixing length, $q=\sqrt{2 e}$, $e$ denotes TKE, and $S_{m}$ is a stability function for momentum. Similarly, eddy diffusivities for scalars is $K_{h}=L q S_{h}$, where $S_{h}$ is a stability function for heat and moisture. In MYNN, the TKE prognostic equation takes the form of

$$
\begin{aligned}
\frac{\partial q^{2}}{\partial t}= & \underbrace{-\mathbf{V} \cdot \nabla q^{2}}_{\text {TKE ADV }}+\underbrace{2 \frac{g}{\theta_{v}} \overline{w^{\prime} \theta_{v}^{\prime}}}_{\text {BUOY }}-\underbrace{2\left(\overline{u^{\prime} w^{\prime}} \frac{\partial u}{\partial z}+\overline{v^{\prime} w^{\prime}} \frac{\partial v}{\partial z}\right)}_{\text {SHEAR }} \\
& -\underbrace{\frac{\partial\left(\overline{w^{\prime} q^{2}}\right)}{\partial z}}_{\text {TRANS }}-\underbrace{2 \varepsilon}_{\text {DISS }},
\end{aligned}
$$

where the first term on the right-hand side (hereafter abbreviated as rhs) denotes TKE advection. The other terms on the rhs denote buoyancy production, shear production, turbulence transport of TKE, and parameterized dissipation of TKE, respectively; the formulations of these terms can be found in Nakanishi and Niino (2004).

As an extension and improvement of its predecessor MellorYamada-type PBL scheme (e.g., Mellor and Yamada 1974, 1982), a series of new features have been added in the MYNN PBL scheme, including an eddy-diffusivity/mass-flux (EDMF) option, representation of subgrid-scale clouds, interaction with clouds, and coupling with other model components (see details in Olson et al. 2019). A recent study that evaluated MYNN using LESs indicates that the sophisticated mixing-length parameterization in

\footnotetext{
${ }^{1}$ Hereafter, TKE refers specifically to the subgrid turbulence kinetic energy predicted by the MYNN PBL scheme.
} 
(a)

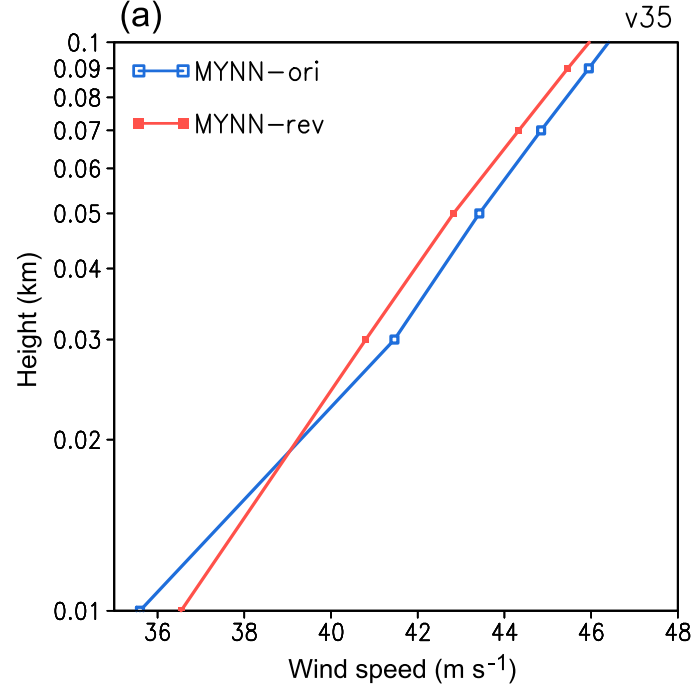

(c)

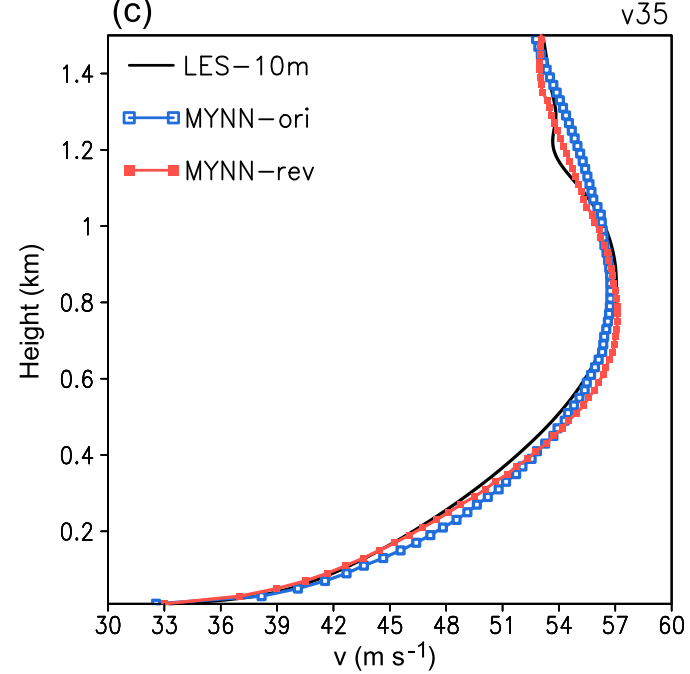

(b)

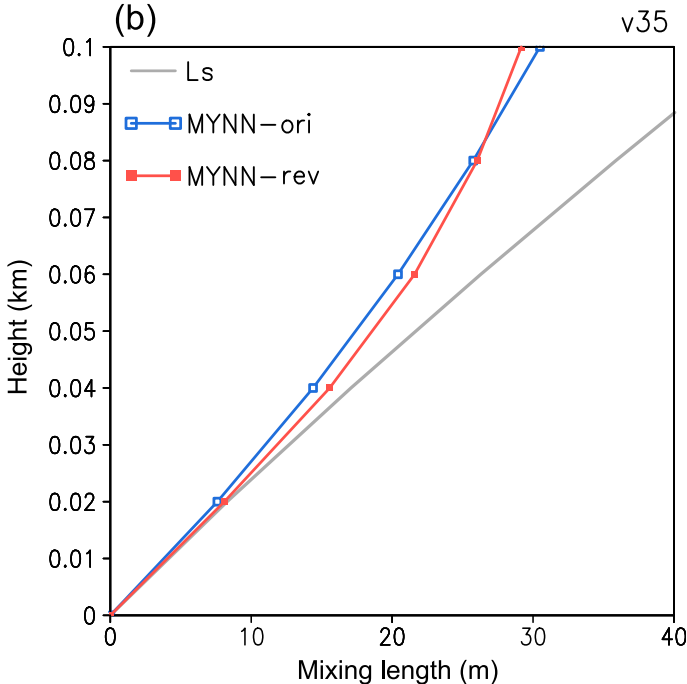

(d)

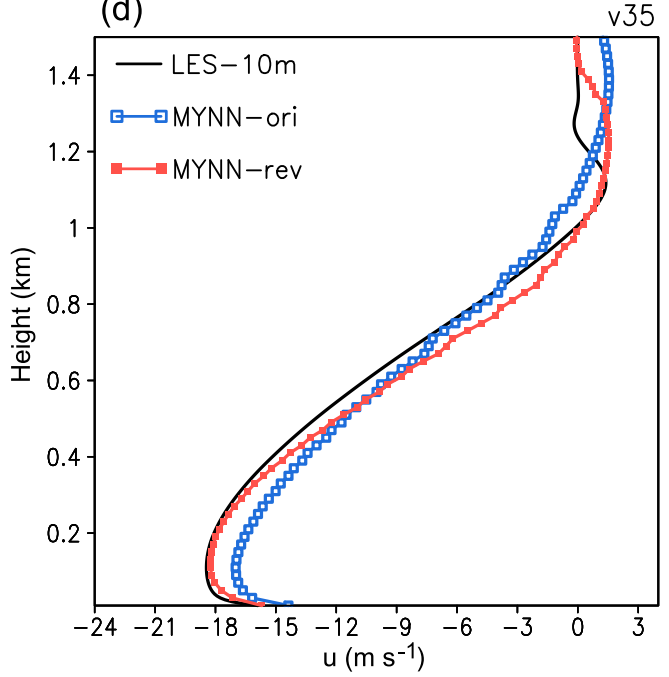

FIG. 2. (a) Vertical profiles of the horizontal wind speed within 10-100-m height from the original MYNN3.0 (blue) and revised MYNN3.0 (red). (b) Vertical profiles of surface length scale $L_{s}$ (gray), master mixing length $L$ from the original (blue) and revised (red) MYNN3.0, respectively. (c),(d) As in (a), but for tangential wind ( $\mathrm{m} \mathrm{s}^{-1}$ ) and radial wind $\left(\mathrm{m} \mathrm{s}^{-1}\right)$, respectively, within 10-1500-m height. The black line denotes the results from a large-eddy simulation. The $z$ axis in (a) uses a log scale to better illustrate the excessive shear near the surface in the original MYNN3.0.

MYNN performs well for the modeling of TC boundary layer (X. Chen et al. 2021, unpublished manuscript).

Before proceeding, we perform single-column model (SCM) simulations, following the method of Bryan et al. (2017) and Chen et al. (2021a). The SCM simulations are initialized with composite thermodynamic profiles outside the eyewall of category 4-5 hurricanes $(r=75 \mathrm{~km})$. Additional SCM simulations at other radii produce similar results (not shown). The MYNN scheme produced near-surface wind profiles that do not exhibit logarithmic characteristics that are typically observed in TCs (e.g., Richter et al. 2021), with excessive wind shear in the lowest two model levels (Fig. 2a). Of note, the near-surface layer in different high-wind conditions is nearly neutrally stratified, as indicated by a very small surface stability parameter $\zeta=z_{b} / L \approx-1 \times 10^{-3}$, where $z_{b}$ is the height of the lowest model level and $L$ is Monin-Obukhov length.

By carefully examining the MYNN code, we improve the near-surface wind profile by including the buoyancy production from surface heat fluxes in the TKE budget at the bottom model level, and by adopting a different "blending" method for $L$. The original formulation for $L$ in MYNN is determined by a harmonic average of different length scales: $L^{-1}=L_{s}^{-1}+L_{t}^{-1}+L_{b}^{-1}$, where $L_{s}, L_{t}$, and $L_{b}$ denote surfacelayer, turbulent, and buoyancy length scale, respectively. The mixing length $L$ will asymptotically approach $L_{s}(\approx k z)$ in the surface layer when height $z$ approaches zero; $k$ is the von Kármán constant $(=0.4) . L_{b}$ is gradually replaced by BouLac mixing length $L_{\mathrm{BL}}$ (Bougeault and Lacarrere 1989) in the 
300-m entrainment layer above the diagnosed boundary layer height. This harmonic averaging can result in substantial reduction in the mixing length compared to the magnitude of the smallest length scale (Olson et al. 2019). We adopt a different way of harmonic averaging, i.e., $L^{-2}=L_{s}^{-2}+L_{t}^{-2}+L_{b}^{-2}$, following Mason and Thomson (1992). This method limits the reduction of mixing length near the surface, and the mixing length in the revised MYNN is closer to $L_{s}$ below 80 -m height (Fig. 2 b). The constant $\alpha_{1}$ in $L_{t}$ [Eq. (10) in Olson et al. 2019] is accordingly changed from 0.23 by default to 0.1 as in Mellor and Yamada (1974). Preliminary tests show that MYNN with these changes has more realistic wind profiles in the near-surface layer and upper boundary layer (Figs. 2c,d). Of note, results from SCMs are verified against the LESs (black lines in Fig. 2). These LESs use 10-m grid spacing and are described further in Chen et al. (2021a).

In this study, we use the level 3 version of MYNN, which includes predictive equations for second-order turbulent quantities (specifically, for temperature variance, water vapor variance, and temperature-vapor covariance). This version of MYNN also includes countergradient diffusion terms [see Nakanishi and Niino (2004) for details].

\section{Experiment design and model setup}

The numerical model used in this study is version 20 of the compressible and nonhydrostatic Cloud Model 1 (CM1; Bryan and Fritsch 2002). The MYNN code in CM1 was obtained from the recently released WRF Model, version 4.2, with additional improvements as discussed in section 2. One upgrade feature in this MYNN code is that with the EDMF option turned on, the mass-flux component of the vertical turbulent flux is gradually turned off at high wind conditions ${ }^{2}$ (e.g., hurricanes). The massflux component of this PBL scheme only activates in thermodynamically unstable conditions, and is not expected to have a large influence inside TCs.

The model is set up on an $f$ plane with a Coriolis parameter of $5 \times 10^{-5} \mathrm{~s}^{-1}$. One model domain is used, and the

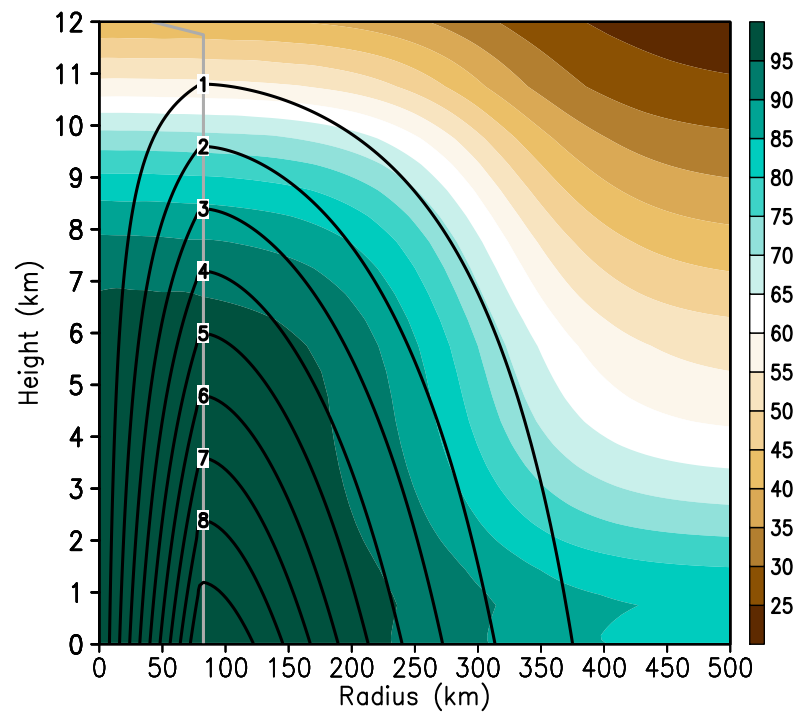

FIG. 3. The radius-height distribution of azimuthally averaged relative humidity (shading, \%) and tangential wind (contour, $\mathrm{m} \mathrm{s}^{-1}$ ) of the initial vortex.

horizontal grid spacing is $3 \mathrm{~km}$ within the central $600 \mathrm{~km} \times$ $600 \mathrm{~km}$ area, beyond which the horizontal grid spacing is gradually stretched from 3 to $15 \mathrm{~km}$ in the outer portion of the domain. The domain coverage is $2400 \mathrm{~km} \times 2400 \mathrm{~km}$. The vertical grid has 59 vertical levels. The vertical grid spacing is gradually stretched from 50 to $500 \mathrm{~m}$ below $5500-\mathrm{m}$ height, and remains as $500 \mathrm{~m}$ from $5500-\mathrm{m}$ height to the model top (i.e., $25 \mathrm{~km}$ ).

We perform two experiments, one includes TKE advection (i.e., CTL experiment) and the other one excludes it (i.e., NoADV experiment). Each experiment is initialized with a moist tropical sounding (Dunion 2011), and sea surface temperature (SST) is set to $29^{\circ} \mathrm{C}$. The radial profile of the tangential wind of the initial vortex follows a modified Rankine vortex:

$$
V(r)=\left\{\begin{array}{cc}
V_{m} \frac{r}{r_{m}}, & r \leq r_{m} \\
V_{m} \frac{r}{r_{m}} \exp \left\{\frac{1}{B}\left[1-\left(\frac{r}{r_{m}}\right)^{B}\right]\right\}-\frac{r-r_{m}}{r_{0}-r_{m}} \exp \left\{\frac{1}{B}\left[1-\left(\frac{r_{0}}{r_{m}}\right)^{B}\right]\right\}, & r>r_{m}
\end{array}\right.
$$

where $V_{m}$ is the maximum tangential wind, $r_{m}$ is the RMW, $r$ is the radius, and $r_{0}$ is the radius where tangential winds vanish. The parameter $B$ determines the decay rate of the tangential wind outside the $r_{m}$; the larger value of $B$ corresponds to a

\footnotetext{
${ }^{2}$ In the MYNN PBL scheme, the mass-flux (MF) component is turned on when bl_mynn_edmf $=1$, and the mixing length is designed to best work with the activated mass-flux component by setting bl_mynn_mixlength $=2$.
}

faster decay rate. The vortex depth is set to $12 \mathrm{~km}$ and $V_{m}$ is set to decrease linearly from the surface to $12-\mathrm{km}$ height. In these two experiments, $V_{m}=10 \mathrm{~m} \mathrm{~s}^{-1}$ near the surface, $r_{m}=80 \mathrm{~km}$, and $B=1.0$. The initial relative humidity is set to $98 \%$ within the inner core $(r<100 \mathrm{~km})$, beyond which the RH gradually decreases to the environmental relative humidity (Fig. 3). This setup is designed to skip the preconditioning stage, when the inner core is typically unsaturated (i.e., "phase I" of Peng et al. 2019), and focuses on the rapid deepening ("phase II" of Peng et al. 2019) and mature stages of the simulated TCs. 
The other physics parameterization schemes used in these two experiments include the Thompson microphysics scheme (Thompson et al. 2008), the RRTMG longwave and short radiation schemes (Iacono et al. 2008), and the GFDL surfacelayer scheme (Kurihara and Tuleya 1974). The Thompson microphysics scheme is selected given recent evaluation studies show that it works well in the simulations of real TCs and can reasonably reproduce the raindrop size distributions against retrievals from ground-based polarimetric radars (e.g., Brown et al. 2016; Wu et al. 2021). The GFDL surface-layer scheme is selected given its surface drag coefficient $\left(C_{d}\right)$ and surface enthalpy exchange coefficient $\left(C_{k}\right)$ have been modified in recent years to be more consistent with observations in high-wind conditions (e.g., Powell et al. 2003; French et al. 2007; Bell et al. 2012; Richter et al. 2016).

To test the robustness of results based on the analysis of two experiments, other sets of experiments with TKE advection on/off are conducted by varying $V_{m}, r_{m}, B, \mathrm{SST}$, microphysical scheme, and relative humidity within the inner core. The findings in these sensitivity experiments are consistent with the findings from the CTL and NoADV simulations (not shown), and hereafter we focus only on the analysis of these two simulations.

\section{Results}

\section{a. Intensity and structural evolution}

Figures $4 \mathrm{a}$ and $4 \mathrm{~b}$ show the evolution of TC intensity and RMW of the simulated TCs in CTL and NoADV. Of note, the TC center is defined by the grid point that produces the maximum tangential wind speed in azimuthally averaged analyses. ${ }^{3}$ Both TCs intensify from the beginning of the simulations, consistent with earlier findings that the nearly saturated core is a prerequisite of TC intensification (e.g., Rappin et al. 2010; Kilroy et al. 2017; Chen et al. 2019; Peng et al. 2019). The difference in the 10-m maximum azimuthal-mean tangential wind between the two experiments appears after $t=55 \mathrm{~h}$ : the CTL TC further intensifies and reaches a quasi-steady state after $t=70 \mathrm{~h}$; in comparison, the NoADV TC reaches a quasisteady state and maintains it until $t=120 \mathrm{~h}$. The RMW of the CTL TC remains slightly smaller than that of the NoADV TC throughout the simulation. One additional phenomenon to note is that the CTL TC has a smaller radius of gale-force wind (i.e., R34) after $110 \mathrm{~h}$ (see Fig. 4c).

Figure 5 compares the evolution of azimuthally averaged 1-km radar reflectivity and $10-\mathrm{m}$ tangential wind between the two experiments. The CTL TC generally has higher radar reflectivity and stronger tangential winds near/inside the RMW than the NoADV TC after $t=30 \mathrm{~h}$ (Fig. 5c). Besides the differences in TC intensity and radar reflectivity, another notable difference between the two experiments lies in the variation of RMW (see white line in Figs. 5a,b) after $t=65 \mathrm{~h}$ : in CTL the

\footnotetext{
${ }^{3}$ This is the default option for determining azimuthally averaged fields in CM1, which typically results in smooth tracks of the TC center over time.
}
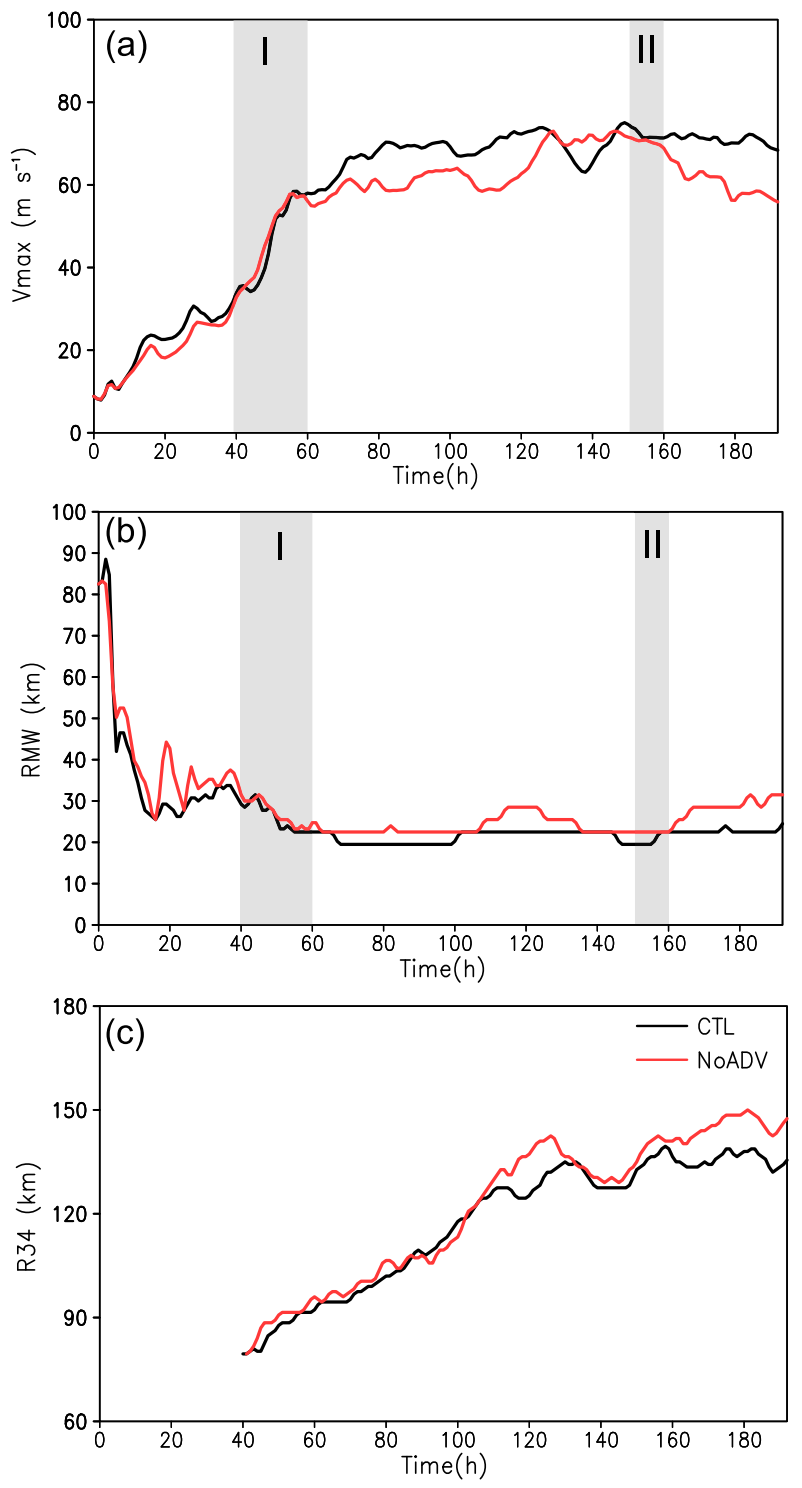

FIG. 4. Evolution of (a) 10-m maximum azimuthal tangential wind ( $\mathrm{m} \mathrm{s}^{-1}$ ), (b) RMW (km), and (c) R34 (km) from CTL (black) and NoADV (red) experiments. The gray-shaded boxes in (a) and (b) denote two analysis periods in this study. The legend for the three panels is shown in (c). R34 in (c) is shown after the simulated $\mathrm{TC}$ reaches hurricane intensity.

RMW varies only slightly, while in NoADV notable RMW expansion occurs twice, i.e., over $t=110-120$ and $160-192 \mathrm{~h}$ (Fig. 4b). To understand the effect of TKE advection on these differences, the following section presents an examination of turbulence properties, inflow structure, and microphysics diabatic heating.

\section{b. Turbulence properties and inflow structure}

Figures 6 and 7 compare the radius-height distribution of azimuthally averaged TKE and $K_{m}$ from the two experiments over $t=40-60$ and $150-160 \mathrm{~h}$, respectively. To reduce the impact of different TC intensity and inner-core size (i.e., 

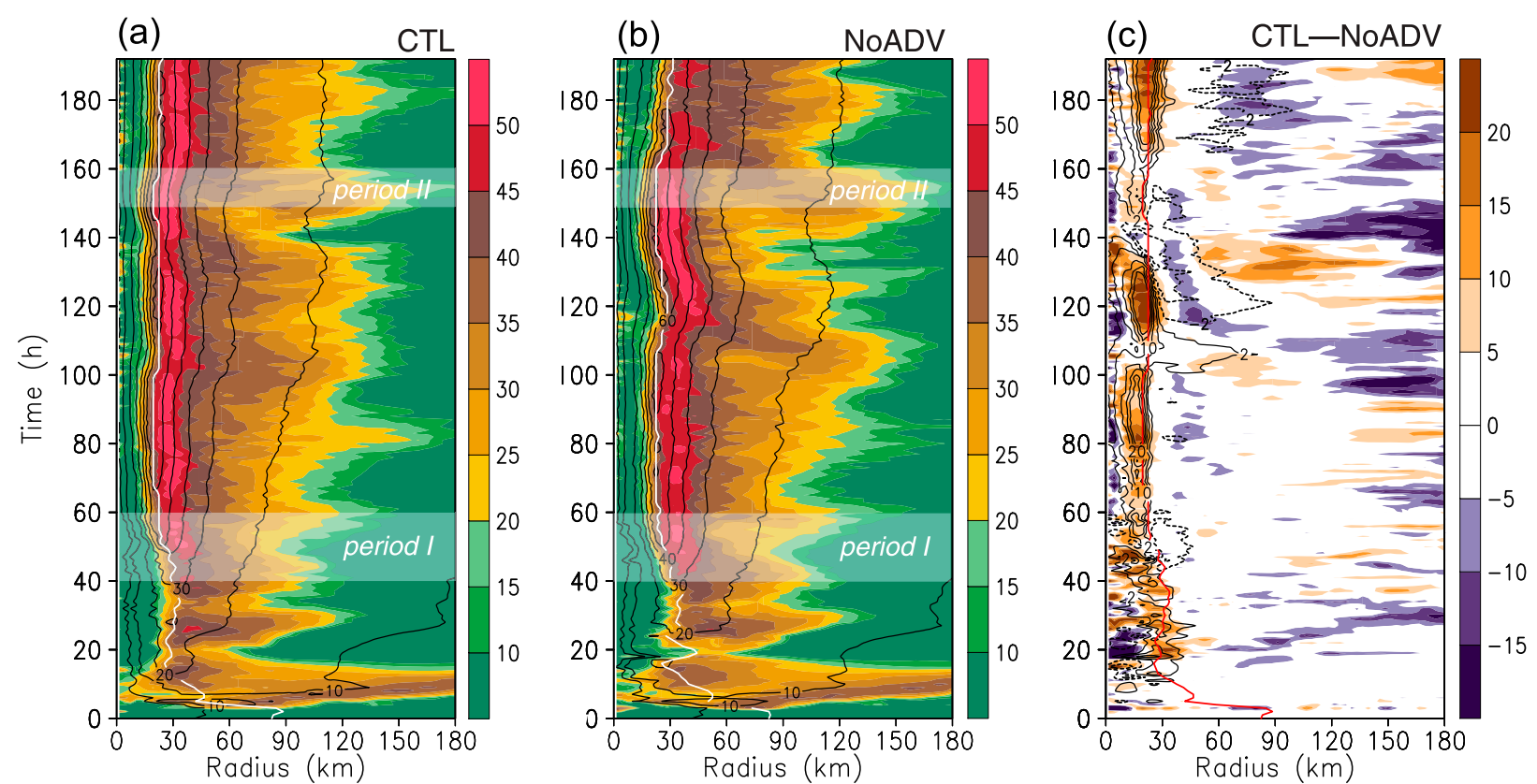

FIG. 5. Hovmöller diagram of azimuthally averaged 1-km radar reflectivity (shading, $\mathrm{dBZ}$ ) and 10-m tangential wind (contours, with values of $5,10,20,30,40,50,60$, and $70 \mathrm{~m} \mathrm{~s}^{-1}$ ) for (a) CTL and (b) NoADV experiments. The white shading denotes the two analysis periods. (c) Differences in the 1-km radar reflectivity (shading) and 10-m tangential wind (contours, with value of $-5,-2,2,5,10,15,20$, $25 \mathrm{~m} \mathrm{~s}^{-1}$; negative values are dashed) between the two experiments (CTL - NoADV). The white line in (a) and (b) denotes RMW. The red line in (c) denotes the RMW in CTL.

RMW) on the difference in turbulence properties, we select these two analysis periods over which the TC intensity and RMW from the two experiments are similar (Figs. 4a,b). Of note, period I (i.e., $t=40-60 \mathrm{~h}$ ) is immediately prior to the occurrence of notable difference in TC intensity and inner-core size between the two experiments. Over period I TC intensification rate is the largest; in comparison, over period II the simulated TCs do not intensify.

Over period I, one striking difference in the TKE distribution between the two experiments is that the "tower-like" structure of TKE in the eyewall extends to higher levels in CTL (Figs. 6a,b), which is more similar to the observed structure (Fig. 1). The region of TKE $>1 \mathrm{~m}^{2} \mathrm{~s}^{-2}$ in the eyewall of the CTL TC extends vertically to $\sim 7 \mathrm{~km}$, which is nearly $2.5 \mathrm{~km}$ higher than that of the NoADV TC. Figure $6 \mathrm{c}$ clearly shows that the CTL TC has larger TKE values (2$6 \mathrm{~m}^{2} \mathrm{~s}^{-2}$ ) along the eyewall updraft, particularly above the 2-km height, suggesting the impact of vertical advection of TKE. The other notable difference lies in the inflow layer near the surface $(z<1 \mathrm{~km}$, see Figs. 9a,b), as the CTL TC has slightly smaller TKE values outside the RMW and larger TKE values inside the RMW (Fig. 6c).

To demonstrate that the difference in the TKE distribution between the two experiments over period $\mathrm{I}$ is contributed by TKE advection term, Figs. 8a and 8b show the composite TKE advection tendency from CTL and the difference in the local time tendency of TKE (i.e., $\partial e / \partial t$ ) between the two experiments over period I. The difference in $\partial e / \partial t$ between the two experiments (Fig. 8b) resemble the pattern of the difference in TKE (Fig. 6c) and also resemble the pattern of TKE advection
(Fig. 8a). Further decomposition of TKE advection tendency into radial and vertical advection of TKE indicates that in CTL the larger TKE values along the eyewall updraft above $2-\mathrm{km}$ height is attributable to vertical advection of TKE (Fig. 8d). The difference in TKE within the inflow layer is related to horizontal advection of TKE (Fig. 8c), since TKE peaks near the RMW and boundary layer inflows advect smaller TKE from large radii toward the RMW and meanwhile advect the peak TKE beneath the eyewall radially inward. This process partly accounts for the much smaller TKE (by $6 \mathrm{~m}^{2} \mathrm{~s}^{-2}$ ) near the RMW and beneath 1-km height in CTL. The vertical advection of TKE is a more dominant contributor to the much smaller TKE in the eyewall beneath 1-km height (Fig. 8d) since TKE is maximized at $\sim 1.5-\mathrm{km}$ height and smaller TKE from below is advected upward into that region in CTL (Fig. 6a). Above the inflow layer within the eyewall region, radial outflow advects large TKE inside the RMW outward, which accounts for the negative TKE tendency inside the RMW and positive TKE tendency outside the RMW within the $1-2-\mathrm{km}$ layer (Figs. 8a,c).

The difference in the $K_{m}$ distribution between the two experiments over period I resembles the differences in TKE (Figs. 6df). The region of $K_{m}>20 \mathrm{~m}^{2} \mathrm{~s}^{-1}$ in the eyewall of the CTL TC extends vertically to $\sim 9 \mathrm{~km}$, which almost doubles that of the NoADV TC. Meanwhile, $K_{m}$ in the inflow layer in CTL is smaller than in NoADV outside the RMW, but larger inside the RMW (Fig. 6f). The similarity in the distribution of TKE and $K_{m}$ is due to the fact that $K_{m}$ is proportional to TKE [see Eq. (1)].

Over period II, the maximum TKE and $K_{m}$ values in the eyewall are $>40 \mathrm{~m}^{2} \mathrm{~s}^{-2}$ and $>400 \mathrm{~m}^{2} \mathrm{~s}^{-1}$, respectively (Fig. 7), 

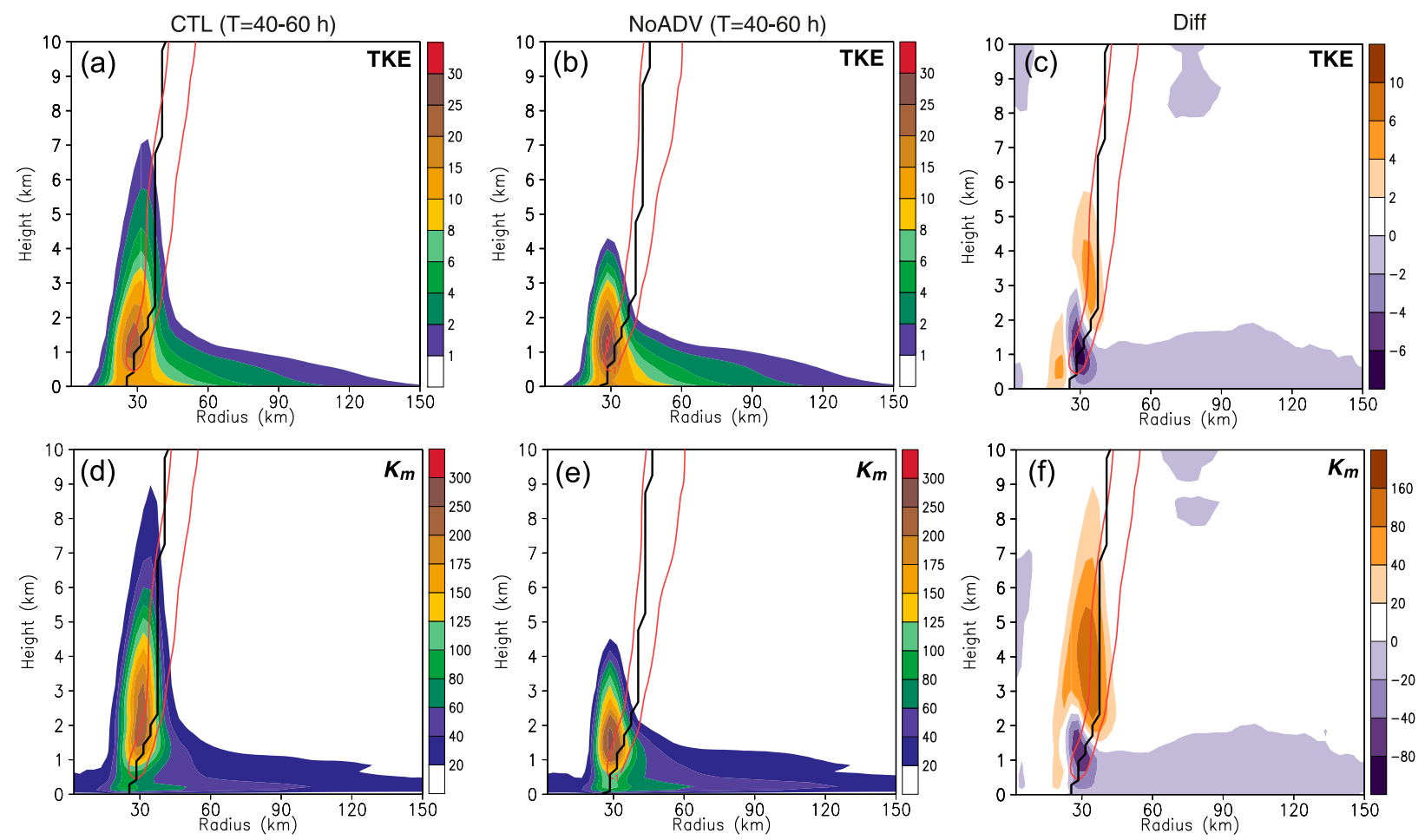

FIG. 6. (a),(b) Radius-height distribution of azimuthally averaged subgrid TKE (shading, $\mathrm{m}^{2} \mathrm{~s}^{-2}$ ) over $t=40-60 \mathrm{~h}$ for the CTL and NoADV experiments, respectively. (c) The difference in the distribution of TKE between the two experiments (i.e., CTL - NoADV). (d)-(f) As in (a)-(c), but for $K_{m}$ (shading, $\mathrm{m}^{2} \mathrm{~s}^{-1}$ ). In each panel, the red contour denotes $w=1 \mathrm{~m} \mathrm{~s}^{-1}$ and the black line denotes the RMW. In (c) and (f), the RMW and $w$ contours are from CTL.

which are much larger than those over period I. These larger values are closely related to the stronger TC intensity over period II (Fig. 4a). Nevertheless, the distributions of TKE and $K_{m}$ in the two experiments, as well as the differences between the two experiments, strongly resemble those in period I, suggesting that the identified differences over period I are robust.

Previous numerical studies have demonstrated that $K_{m}$ in the boundary layer regulates the inflow strength (Foster 2009; Smith and Thomsen 2010; Kepert 2012; Gopalakrishnan et al. 2013; Zhang et al. 2015), as smaller $K_{m}$ and the resulting stronger friction induce stronger boundary layer inflows. However, this phenomenon is barely detectable over period I (Figs. 9a,b). Despite the smaller values of $K_{m}$ outside the RMW of the CTL TC, the inflow strength is generally comparable between the two experiments, with the strong inflow $\left(<-12 \mathrm{~m} \mathrm{~s}^{-1}\right)$ in NoADV extending to a slightly larger radius. Additionally, the inflow depth in NoADV is slightly deeper than CTL near the eyewall. This seemingly contradictory result is primarily ascribed to the stronger diabatic heating within the eyewall in NoADV over period I (Figs. 10a,b).

As another measure of radial inflow, and to compare with observations, we analyze the near-surface inflow angle over period I, when the simulated TCs in both experiments attain category-2 hurricane intensity (Figs. 9c,d). Inflow angle is an insightful metric of the boundary layer inflow, which is defined as $\tan ^{-1}\left(u_{10} / v_{10}\right)$, where $u_{10}$ and $v_{10}$ are the radial and tangential velocities at 10-m height, respectively. For a reference,
Figs. 9c and 9d also show the radial distribution of the composite inflow angle based on 1600 global positioning system (GPS) dropsondes collected in 18 category 1-5 hurricanes (Zhang and Uhlhorn 2012). Over period I, the radial profile of inflow angle from these two experiments are generally comparable to observations outside the RMW, with the simulated inflow angle within $\sim 5^{\circ}$ of the observational average. The maximum inflow angle from these two experiments resides slightly closer to the RMW than observations. The inflow angle outside $2 \times$ RMW from the two experiments is comparable, while the inflow angle near the RMW differs slightly; the inflow angle in CTL is $\sim 2^{\circ}-3^{\circ}$ larger in magnitude than that in NoADV within the annulus of $0.8-1.2 \times \mathrm{RMW}$, suggesting the inflow is accelerated near the RMW in CTL. The slightly larger inflow angle near the RMW in CTL is also found over period II (Fig. 9d), when TCs in both experiments attain category-5 hurricane intensity. Interestingly, over period II, the radial profile of inflow angle outside $2 \times$ RMW from the two experiments is flatter (i.e., does not vary as much with radius) than the composite structure for category 1-5 hurricanes.

The accelerated inflow near the RMW in CTL has a significant implication in the radial location of maximum microphysics diabatic heating. While the maximum diabatic heating in the eyewall of the NoADV TC is stronger over period I (Figs. 10a,b), the CTL TC has stronger diabatic heating at smaller radii radially inward of the RMW (Fig. 10c). Importantly, the enhanced inflow near the RMW and stronger diabatic heating at smaller radii are 

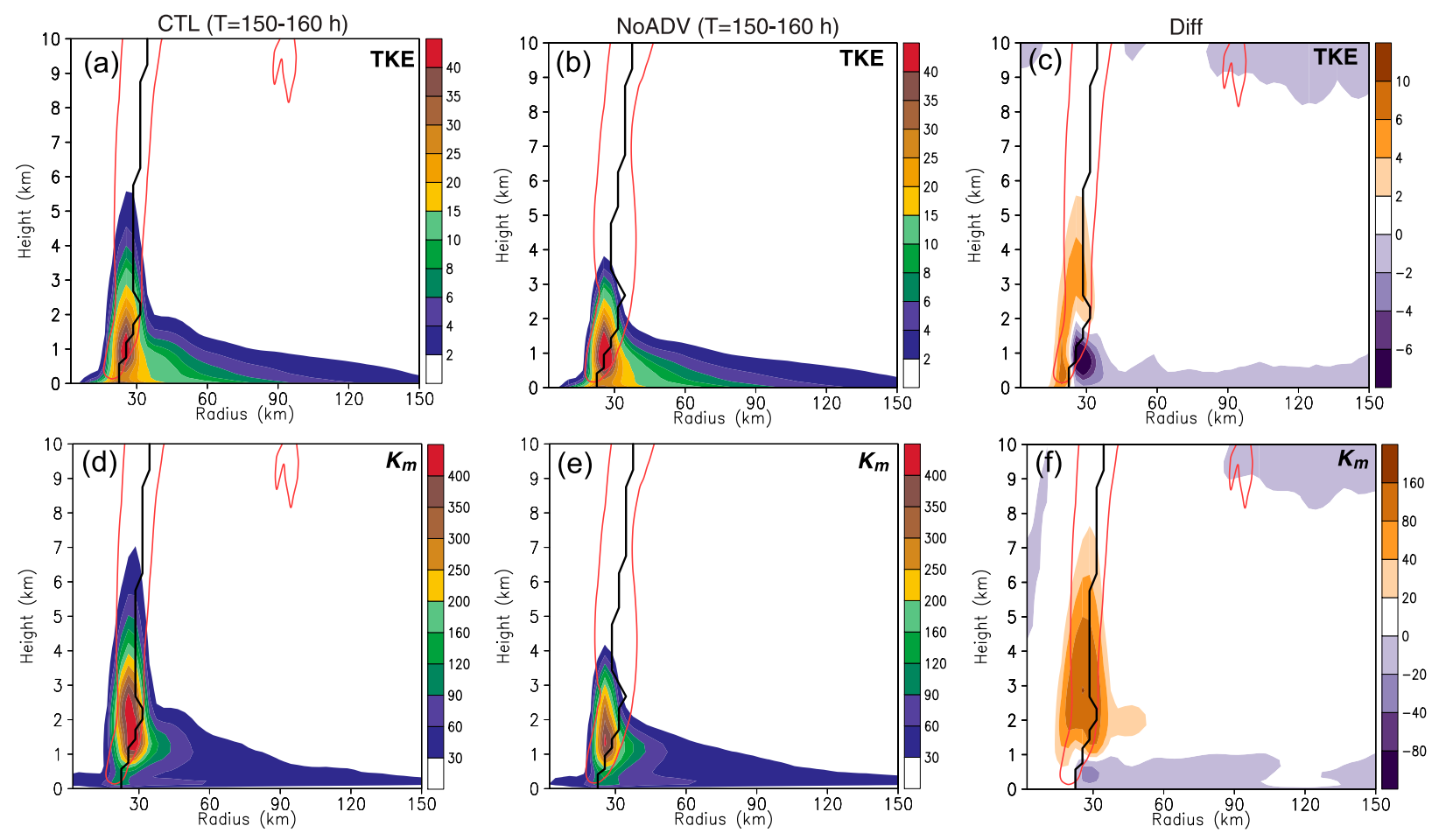

FIG. 7. As in Fig. 6, but for period II, i.e., $t=150-160 \mathrm{~h}$.

also found over period II as well (Figs. 9d and 10d). The diabatic heating at smaller radii is associated with larger absolute angular momentum being drawn inward to smaller radii and further spinup of the TC circulation above the boundary layer (Smith and Montgomery 2016). This dynamical process is confirmed by Figs. 9e and 9f. The absolute angular momentum averaged within the lowest $1 \mathrm{~km}$ within $r=40 \mathrm{~km}$ in CTL is larger than in NoADV (Fig. 9e), and the positive radial advection of angular momentum that peaks outside the RMW also appears at a smaller radius in CTL than in NoADV (Fig. 9f). This dynamical process provides a reasonable explanation for the smaller innercore size and also the stronger TC intensity in CTL after period I (Figs. 4a,b).

The differences in the boundary layer structure and radial location of diabatic heating between the two experiments are fundamentally attributed to the difference in the model setup, i.e., the inclusion (or exclusion) of TKE advection. The inclusion of TKE advection exerts a continuous effect on the turbulence properties including TKE and $K_{m}$ in the boundary layer and in the eyewall (as discussed earlier) from the beginning of the simulation. The larger TKE in the eyewall of the CTL TC also affects the magnitude of the mixing length $L$ in MYNN and thereby indirectly contributes to the larger $K_{m}$. Figure 11a compares the radial profile of the diagnosed boundary layer height from the two experiments over period I. The averaged boundary layer height within the eyewall region $(r=15-45 \mathrm{~km})$ is $\sim 700 \mathrm{~m}$. Of note, the annulus $r=15-45 \mathrm{~km}$ is selected to encompass the region of eyewall updrafts associated with strong diabatic heating (see Figs. 10a,b). Above the 300-m-deep "entrainment layer" near the top of the diagnosed boundary layer height (defined in the MYNN code), $L$ is determined by $0.4 \times L_{\mathrm{BL}}$.

Figures $11 \mathrm{~b}$ and $11 \mathrm{~d}$ show that differences in $K_{m}$ and length scales between the two experiments are mostly above $1.5-\mathrm{km}$ height. Besides the larger TKE, the larger $K_{m}$ above $1.5-\mathrm{km}$ height in CTL (Fig. 11b) is also contributed by larger $L$ (Fig. 11c). Figure 11d further shows that the larger $L$ above 1.5$\mathrm{km}$ height is attributed to the larger $L_{\mathrm{BL}}$. Of note, $L_{\mathrm{BL}}$ represents the maximum possible distance traveled by an air parcel due to the loss of TKE via buoyancy effects, whose magnitude depends crucially on the initial TKE of the air parcel. The $L$ maximum within the 1-2-km layer is closely related to the larger TKE therein. Below $1.5-\mathrm{km}$ height the averaged $K_{m}$ within the eyewall of the CTL TC is slightly smaller than that in the NoADV TC, which is closely related to the smaller TKE therein (Fig. 6c).

\section{c. Roles of horizontal and vertical advection of TKE}

To further investigate the contribution of horizontal and vertical advection of TKE to the differences in TC intensity and structure between CTL and NoADV, additional sensitivity experiments having only vertical (i.e., VADVON) or horizontal (i.e., HADVON) advection of TKE are performed. Figure 12 compares the evolution of TC intensity and RMW from different experiments. In HADVON, the RMW of the simulated TC starts to expand after $t=60 \mathrm{~h}$ and the TC intensification pauses; afterward, the TC intensity in HADVON is generally weaker than VADVON and CTL except for $t=$ $110-150 \mathrm{~h}$. In contrast, the evolution of TC intensity and RMW in VADVON resembles that in CTL, although the maximum 

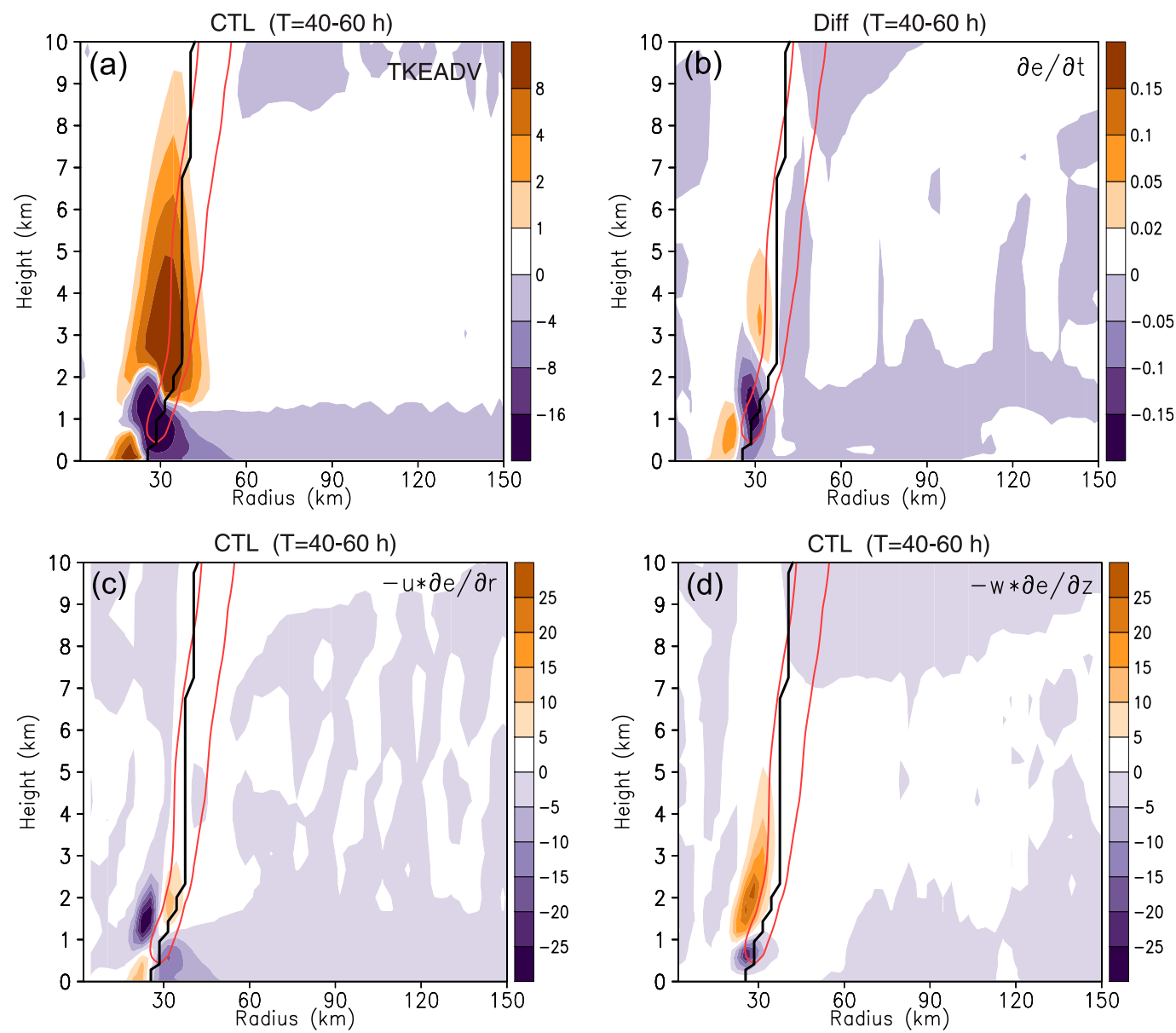

FIG. 8. Radius-height distribution of (a) the total advection of subgrid TKE, (c) radial advection of subgrid TKE, (d) vertical advection of subgrid TKE averaged over $t=40-60 \mathrm{~h}$ from CTL. The unit of the TKE tendency is $10^{-3} \mathrm{~m}^{2} \mathrm{~s}^{-3}$. (b) The difference in $\partial e / \partial t\left(10^{-3} \mathrm{~m}^{2} \mathrm{~s}^{-3}\right)$ between the two experiments (i.e., CTL - NoADV). The black line denotes RMW and the red contour denotes $w=1 \mathrm{~m} \mathrm{~s}^{-1}$.

intensity in VADVON is slightly weaker than in CTL over $t=$ $60-150 \mathrm{~h}$.

Figure 13 compares the distribution of TKE and $K_{m}$ from HADVON and VADVON averaged over $t=50-60 \mathrm{~h}$, when the TC intensity evolution in the two experiments starts to diverge but the RMW is similar (Fig. 12). Not surprisingly, the TKE "tower" within the eyewall in VADVON is much taller and less slantwise than in HADVON (Figs. 13a,b). Recall that the inclusion of TKE advection is associated with a smaller maximum TKE (see Figs. $6 a-c$ and $7 a-c$ ). Thus, one interesting finding in Figs. 13a and 13b is the maximum TKE within the TKE "tower" in VADVON is larger than in HADVON, which is attributable to a lack of radially outward advection of TKE within the 1-2-km layer (see Fig. 8c) in VADVON. As a result, VADVON has notably larger TKE inside the RMW than HADVON, with the maximum difference greater than $10 \mathrm{~m}^{2} \mathrm{~s}^{-2}$ (Fig. 13c). The difference in the $K_{m}$ distribution between VADVON and HADVON is similar to the differences in TKE (Figs. 13d-f).

Figures $14 \mathrm{a}, 14 \mathrm{~b}$, and $14 \mathrm{e}$ show that VADVON has stronger boundary layer inflow than HADVON, especially near the RMW, which is associated with stronger eyewall diabatic heating in VADVON (see Figs. 14c,d), given larger $K_{m}$ in the boundary layer (see Fig. 13f) supports weaker radial inflows and a weaker TC vortex (e.g., Gopalakrishnan et al. 2013; Zhang et al. 2015). While not shown, Hovmöller diagram of radar reflectivity indicates that the eyewall convection in VADVON is generally stronger than in HADVON. The stronger eyewall convective activity and stronger TC intensity in VADVON is mainly attributed to the stronger turbulent mixing above the inflow layer, as shown in Fig. 13f, which is consistent with the findings reported in Zhu et al. (2019).

The enhanced vertical mixing inside the RMW can transport more water vapor upward and help maintain the convective activity therein. Figure 14f shows that inside the RMW of the VADVON TC there is more water vapor above $2-\mathrm{km}$ height and less water vapor below, indicating the role of the enhanced vertical mixing. The less slantwise outflow jet in VADVON (cf. Figs. $14 \mathrm{~b}$ and $14 \mathrm{a}$ ), likely a response to stronger diabatic heating or enhanced vertical mixing $\left(K_{m}\right)$ therein, causes more aligned eyewall updrafts in VADVON and accounts for the lower water vapor along eyewall updrafts in HADVON (Fig. 14f). VADVON also has more water vapor outside the eyewall region and above 
(a)
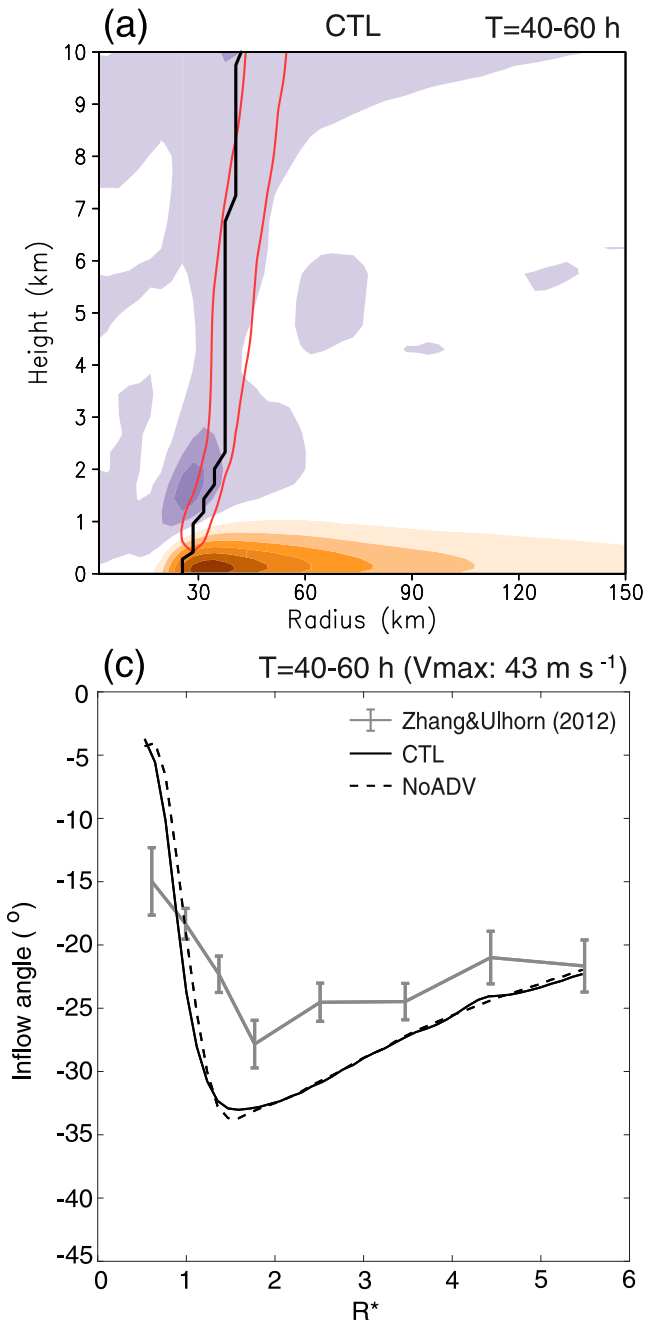

(e)

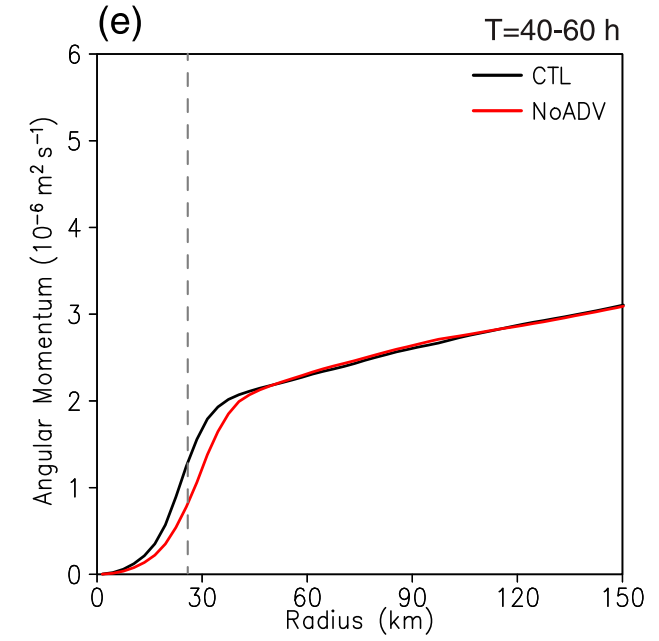

(b)
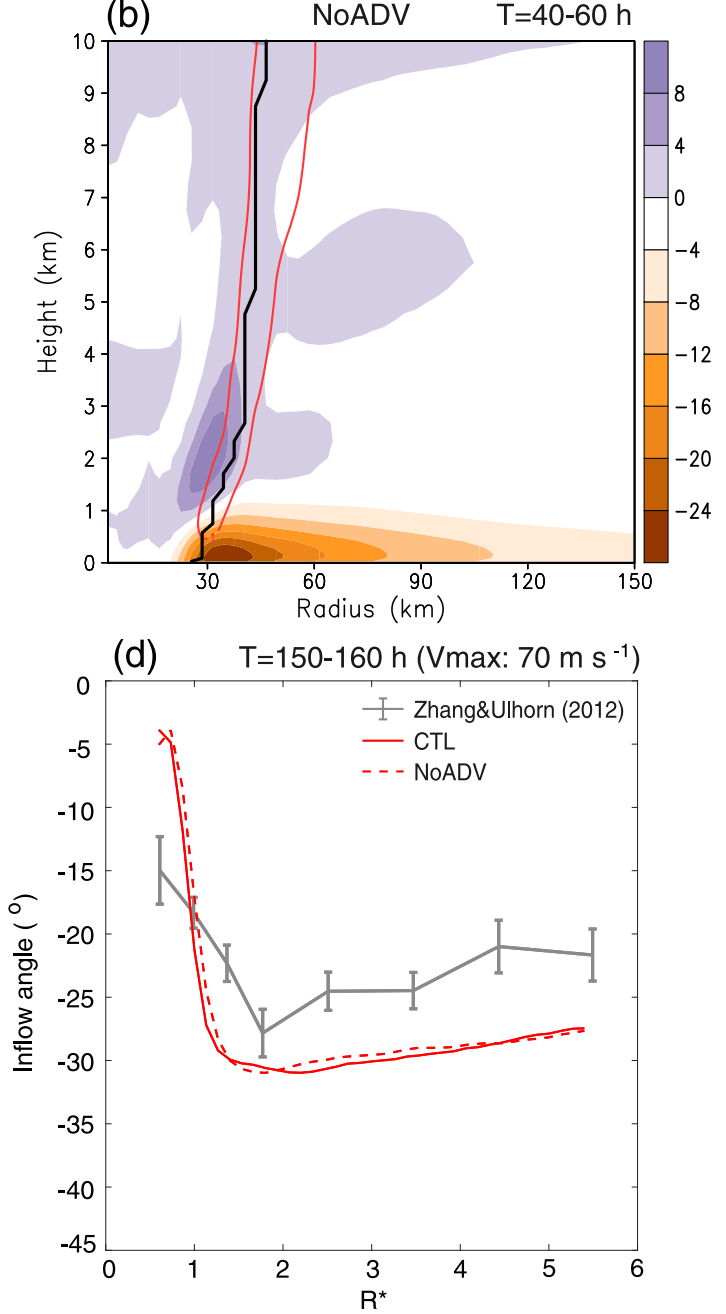

(f)

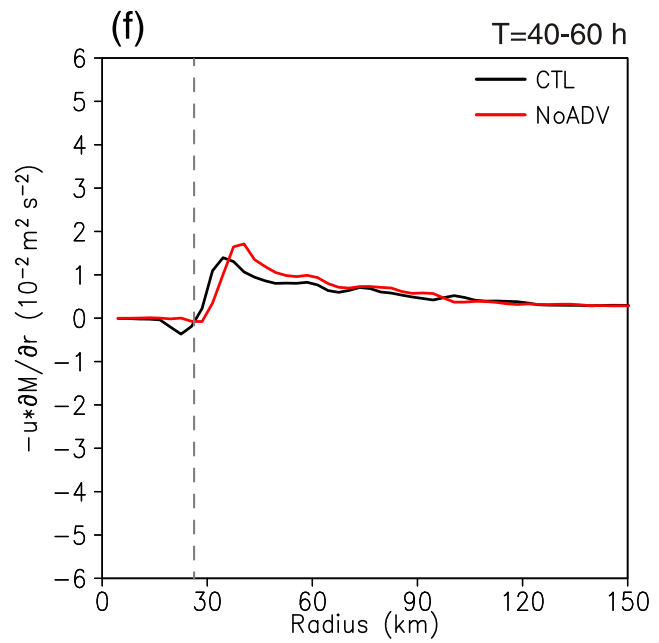

FIG. 9. (a),(b) Composite vertical structure of radial velocity (shading, $\mathrm{m} \mathrm{s}^{-1}$ ) over $t=40-60 \mathrm{~h}$ for CTL and NoADV experiments, respectively. The black line denotes the RMW and the red contour denotes $w=1 \mathrm{~m} \mathrm{~s}^{-1}$. (c),(d) Composite 10-m radial profile of inflow angle $\left({ }^{\circ}\right)$ as a function of normalized radius $R^{*}(=R / \mathrm{RMW})$ over $t=$ 40-60 and 150-160 h, respectively. The solid (dashed) line denotes the CTL (NoADV) experiment. The gray line denotes the $10-\mathrm{m}$ radial profile of inflow angle based on dropsonde composite of cat 1-5 hurricanes (Zhang and Uhlhorn 2012) and the gray bar denotes the $95 \%$ confidence intervals. Composite radial profile of (e) absolute 

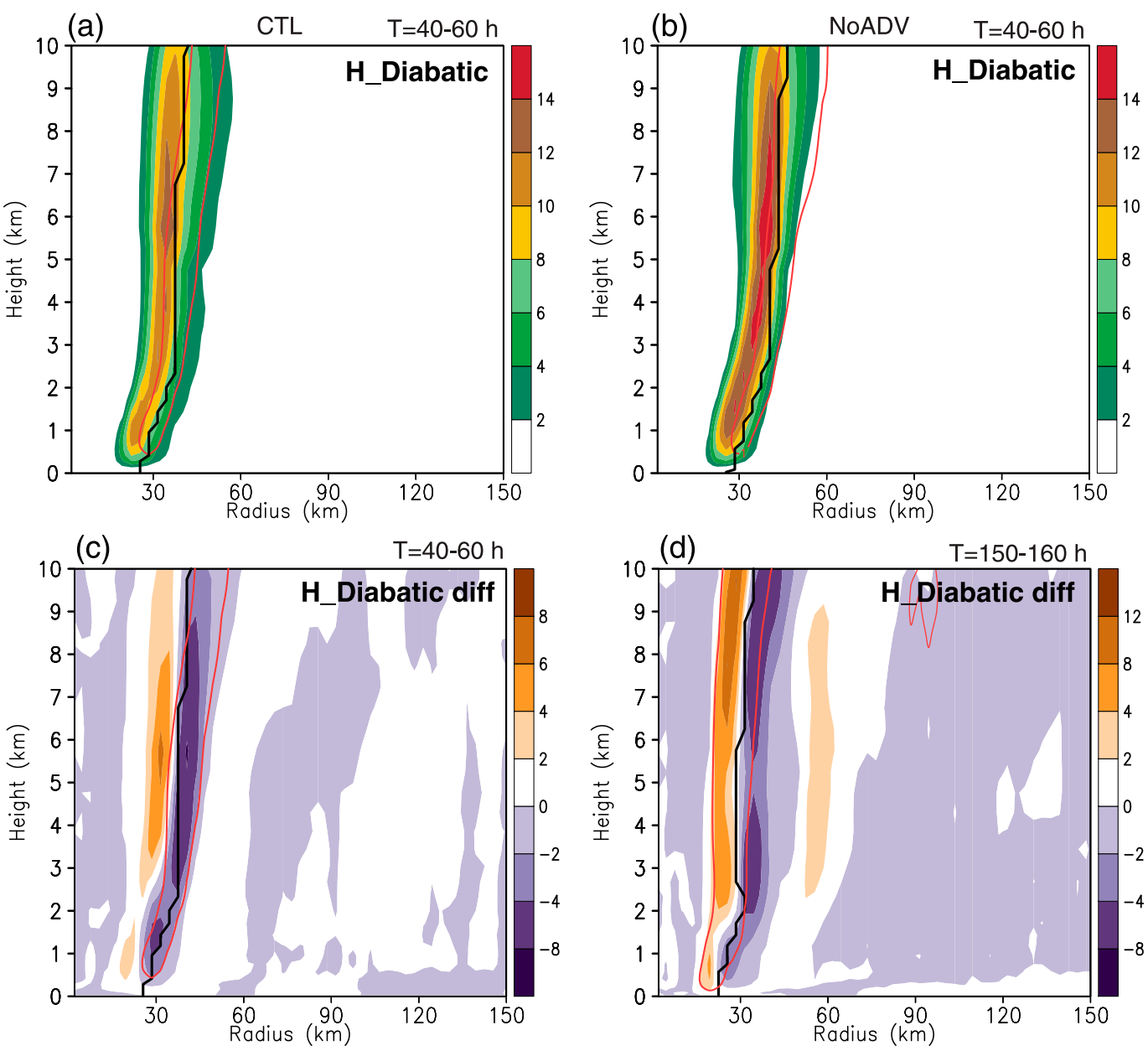

FIG. 10. (a),(b) Composite vertical structure of microphysics diabatic heating $\left(10^{-3} \mathrm{~K} \mathrm{~s}^{-1}\right)$ over $t=40-60 \mathrm{~h}$ for CTL and NoADV experiments, respectively. (c),(d) Difference in the radius-height distribution of microphysics diabatic heating (shading, $10^{-3} \mathrm{~K} \mathrm{~s}^{-1}$ ) between the two experiments (i.e., CTL - NoADV) for $t=40-60$ and 150 $160 \mathrm{~h}$, respectively. Black line denotes the RMW and the red contour denotes $w=1 \mathrm{~m} \mathrm{~s}^{-1}$.

the inflow layer, which may also attribute to more vertical mixing when the vertical advection of TKE is activated and convection is active therein. Another interesting phenomenon to note in Fig. 14e is that while the near-surface RMW in the two experiments is identical, the larger slope of RMW within the 1-4-km layer in VADVON (dashed gray line) than in HADVON (black line) is also closely related to the less slantwise outflow jet in VADVON.

In summary, the above analysis indicates that enhanced vertical mixing in eyewall may affect the eyewall diabatic heating via two effects: on one hand, enhanced vertical mixing above the inflow layer may reduce the tilt of outflow jets as well as the radially outward drift of rising parcels from the boundary layer, thus eyewall updrafts and the associated diabatic heating get closer to the TC center; on the other hand, the enhanced vertical mixing top of the inflow layer can mix more water vapor upward, which creates an idealized environment for the development of deep convection inside the RMW. These effects together contribute to the stronger eyewall diabatic heating inside the RMW, which further contributes to stronger TC intensity and smaller RMW in VADVON than in HADVON. These results also demonstrate that the differences between CTL and NoADV described in sections $4 \mathrm{a}$ and $4 \mathrm{~b}$ are mostly attributable to vertical advection of TKE.

angular momentum $\left(\mathrm{m}^{2} \mathrm{~s}^{-1}\right)$ and (f) radial advection of angular momentum $\left(\mathrm{m}^{2} \mathrm{~s}^{-2}\right)$ averaged within the lowest $1 \mathrm{~km}$ over $t=40-60 \mathrm{~h}$ for CTL (black) and NoADV (red) experiments, respectively. The gray dashed lines in (e) and (f) denote the approximate location of RMW in both experiments. 
(a)

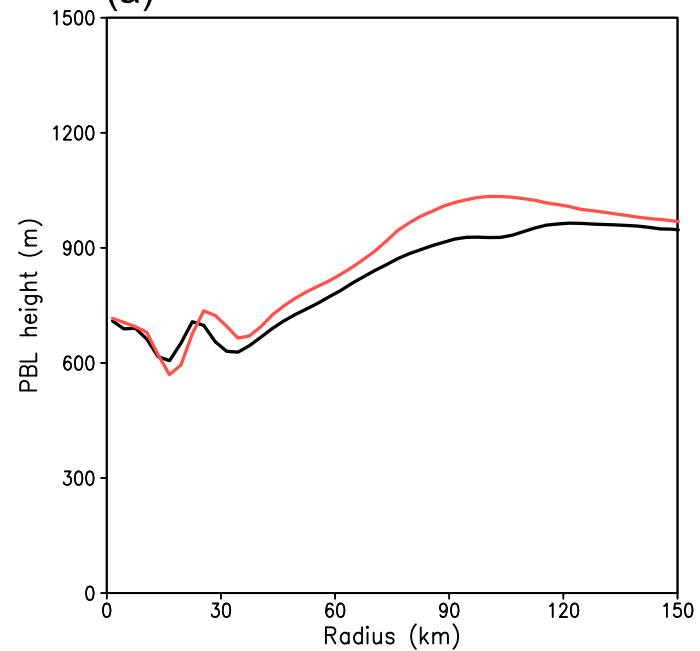

(c)

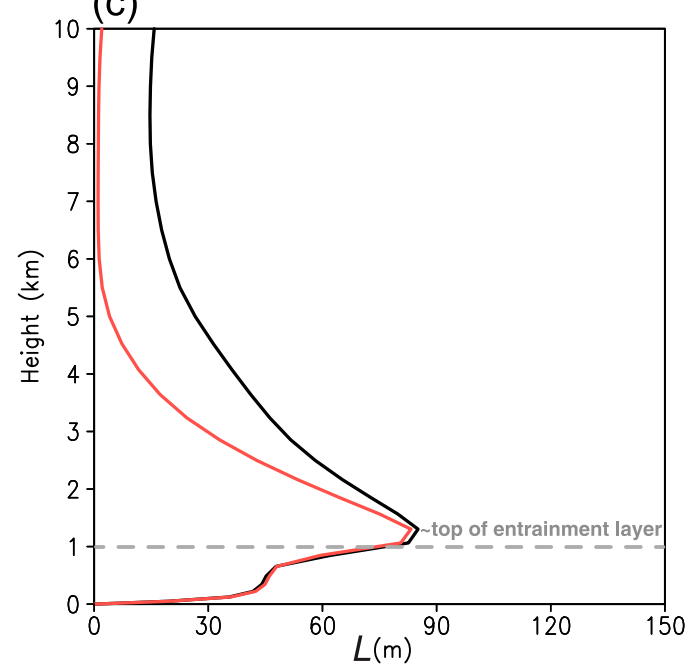

(b)

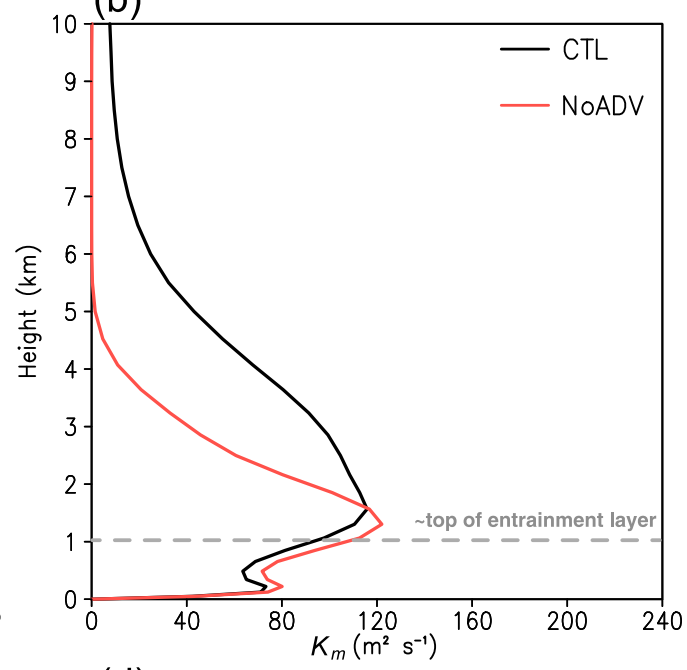

(d)

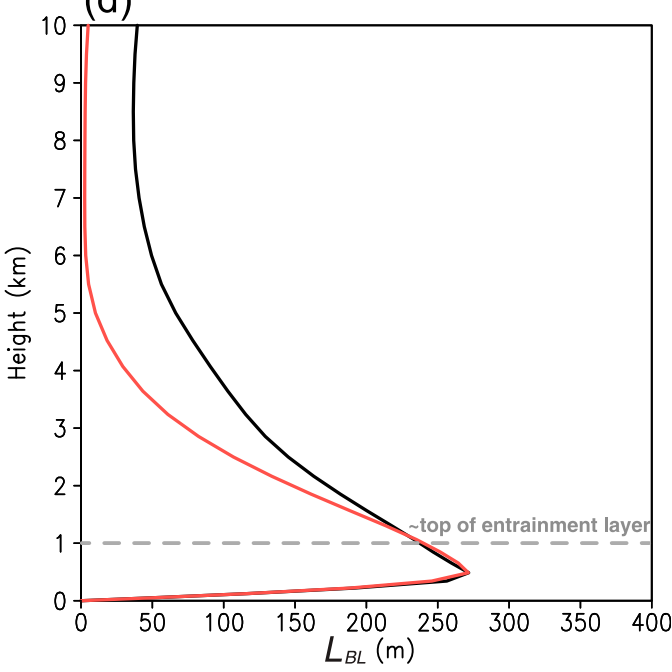

FIG. 11. Comparisons of (a) radial profile of PBL height, and vertical profiles of (b) eddy viscosity $K_{m}\left(\mathrm{~m}^{2} \mathrm{~s}^{-1}\right)$, (c) master mixing length $L(\mathrm{~m})$, and (d) BouLac mixing length $L_{\mathrm{BL}}(\mathrm{m})$ for CTL (black) and NoADV (red) experiments. Results in (b)-(d) are averaged within $r=15-45 \mathrm{~km}$ over period I. The dashed line in (b)-(d) denotes the top of the entrainment layer.

\section{Discussions}

a. What drives the high TKE above the inflow layer in the eyewall region?

The analysis in section 4 indicates that advection of TKE contributes to large TKE above the inflow layer in the eyewall region. To further quantify the roles of other factors and clarify the dynamical processes responsible for the large TKE above the inflow layer in the TC eyewall (Smith and Thomsen 2010; Kepert 2012), we examine the TKE budget in the eyewall. To simplify the interpretation of the results, we divide Eq. (1) by 2 to have the TKE (i.e., $e$ ) budget equation

$$
\frac{\partial e}{\partial t}=-\mathbf{V} \cdot \nabla e+\frac{g}{\theta_{v}} \overline{w^{\prime} \theta_{v}^{\prime}}-\left(\overline{u^{\prime} w^{\prime}} \frac{\partial u}{\partial z}+\overline{v^{\prime} w^{\prime}} \frac{\partial v}{\partial z}\right)-\frac{\partial\left(\overline{w^{\prime} e}\right)}{\partial z}-\varepsilon
$$

The shear production term can be rewritten as

$$
-\left(\overline{u^{\prime} w^{\prime}} \frac{\partial u}{\partial z}+\overline{v^{\prime} w^{\prime}} \frac{\partial v}{\partial z}\right)=K_{m}\left[\left(\frac{\partial u}{\partial z}\right)^{2}+\left(\frac{\partial v}{\partial z}\right)^{2}\right],
$$

and the dissipation term is given by

$$
\varepsilon=\frac{(2 e)^{3 / 2}}{B_{1} L}
$$

where $B_{1}$ is a coefficient. Of note, MYNN uses a formulation of the buoyancy term that accounts for saturated conditions, and includes the liquid and ice content effects.

Figure 15 shows the TKE budget results within the eyewall region $(r=15-45 \mathrm{~km})$ over period I. As mentioned earlier, this annulus is chosen to encompass the eyewall region, which is indicated by strong diabatic heating (Figs. 10a,b). The budget 

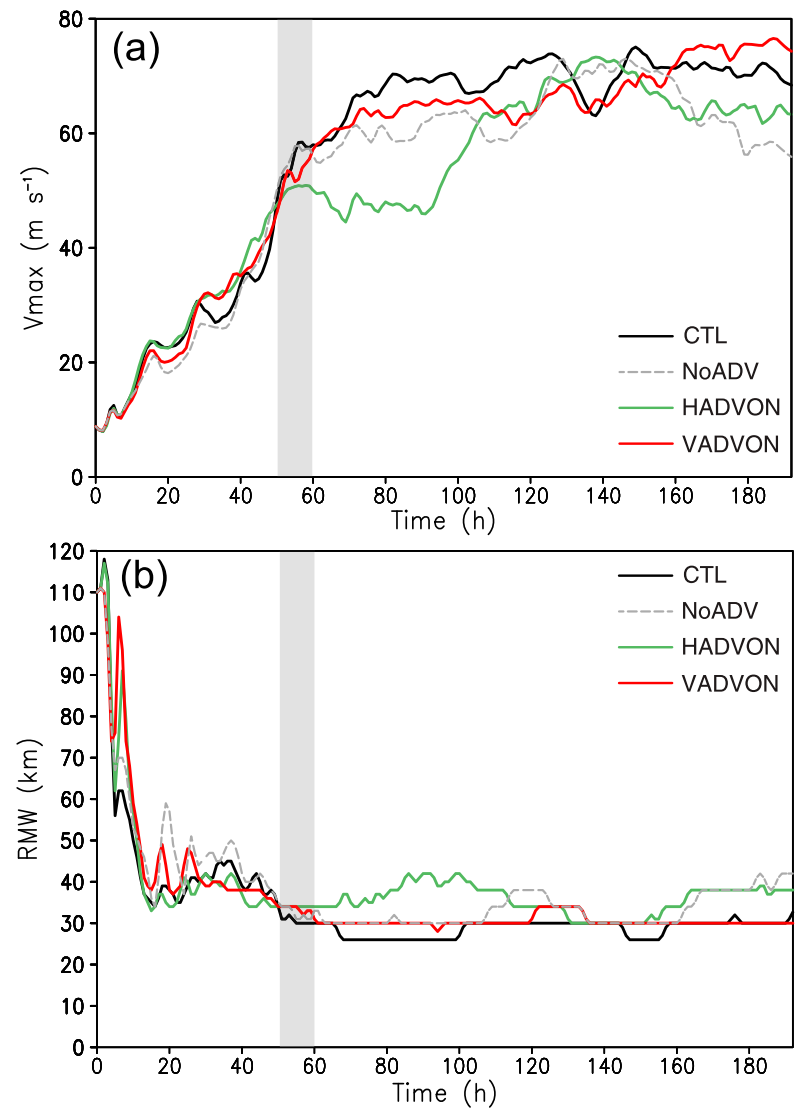

FIG. 12. Evolution of (a) 10-m maximum azimuthal tangential wind ( $\mathrm{m} \mathrm{s}^{-1}$ ), and (b) RMW (km), from CTL (black), NoADV (dashed gray), HADVON (green), and VADVON (red) experiments. The gray-shaded box in (a) and (b) denote the analysis period.

terms from the rhs of Eq. (4) are calculated within the MYNN code, and written as output during the model simulations. We have verified that the sum of the budget terms [rhs of Eq. (4)] is similar to the local time tendency of TKE (i.e., $\partial e / \partial t$ ) to within $1 \times 10^{-4} \mathrm{~m}^{-2} \mathrm{~s}^{-3}$ (not shown), meaning that all sources/sinks of TKE have been determined accurately. Figure 15a indicates that the positive TKE tendency above $2.5-\mathrm{km}$ height in CTL is predominantly contributed by the TKE advection term (red line in Fig. 15a), which remains positive above $\sim 2-\mathrm{km}$ height (i.e., the level of TKE maximum in the eyewall). This finding demonstrates that vertical advection of TKE is primarily responsible for the formation of a taller TKE "tower" within the eyewall of the CTL TC. In comparison, the turbulence transport of TKE (black line in Fig. 15a) contributes only slightly to the positive TKE tendency above $2.5-\mathrm{km}$ height. In contrast, in NoADV, the turbulence transport of TKE is the only contributor to the positive TKE tendency above $3-\mathrm{km}$ height (Fig. 15b); however, it is much smaller in magnitude than the TKE advection term in CTL (cf. Figs. 15a,b).

Within the 1-2-km layer (which is just above the inflow layer), however, shear production of TKE is the dominant contributor to the positive TKE tendency in both experiments (not shown). The sum of shear production and dissipation of TKE terms is maximized near 1-km height (Figs. 15a,b). This is mainly attributed to the $L$ maximum near $1-\mathrm{km}$ height (Fig. 11c), since shear production term is proportional to $L$ while dissipation of TKE is proportional to $L^{-1}$ [see Eqs. (1), (5), and (6)]. Within the inflow layer $(<1 \mathrm{~km})$, the TKE advection term is negative (Fig. 15c) as explained in section 4 .

Interestingly, the buoyancy production term (green line in Fig. 15) remains negative in the eyewall except within the lowest $300 \mathrm{~m}$ in both experiments. To better understand this result, we decompose the buoyancy production term into four subterms (see details in appendix) and show their profiles in the eyewall over $t=40-60 \mathrm{~h}$ in Fig. 16. Results indicate that the negative buoyancy production term in the eyewall is predominantly attributable to the effects of stratification [i.e., the first term on the rhs of Eq. (A3)], as liquid-ice water potential temperature $\theta_{l i}$ increases with height except for the near-surface superadiabatic layer (not shown). The buoyancy production due to vertical gradient of total water content [i.e., the second term on the rhs of Eq. (A3)] is positive, as total water content maximizes near the surface and decreases with height (not shown), but is comparably much smaller in magnitude than the stratification effects. Additionally, buoyancy production due to countergradient fluxes and stratocumuluscloud-top radiative cooling [i.e., the third and fourth terms on the rhs of Eq. (A3)] is negligible compared to the first two terms on the rhs of Eq. (A3).

The findings in this section reveal that the large TKE aloft above the inflow layer within the eyewall is not caused by buoyancy production, which is dominated by negative effects of stratification; instead, the large TKE in the middle troposphere of the eyewall is attributable to TKE advection, turbulence transport, and shear production, consistent with the argument in Smith and Thomsen (2010).

\section{b. Possible further improvement to the PBL schemes with predictive equations for $T K E$}

For this study, we modified the MYNN code to account for buoyancy production term near the surface and adopted a different mixing length blending method (see section 2), both of which help improve the wind profiles, especially in the surface layer and in the mid-upper boundary layer (Figs. 2a,b). Specifically, the simulated wind profile using this modified MYNN exhibits logarithmic characteristics near the surface, which is in sharp contrast to that in the unmodified MYNN code (Fig. 2a). With the inclusion of TKE advection, the simulated TKE distribution in the eyewall in CTL is more consistent with the observations than in NoADV, as discussed above. However, a comparison of Figs. 1 and 6 indicate that TKE in the upper levels within the eyewall of the CTL TC appears to be underestimated with MYNN compared to observations.

The assumption behind the design of one-dimensional (1D) PBL schemes for NWP models is that the horizontal grid spacing is considerably larger than the scale of energycontaining eddies. The subgrid-scale turbulent processes are thereby considered homogeneous horizontally, and 1D PBL schemes typically parameterize only the vertical diffusion (see, 

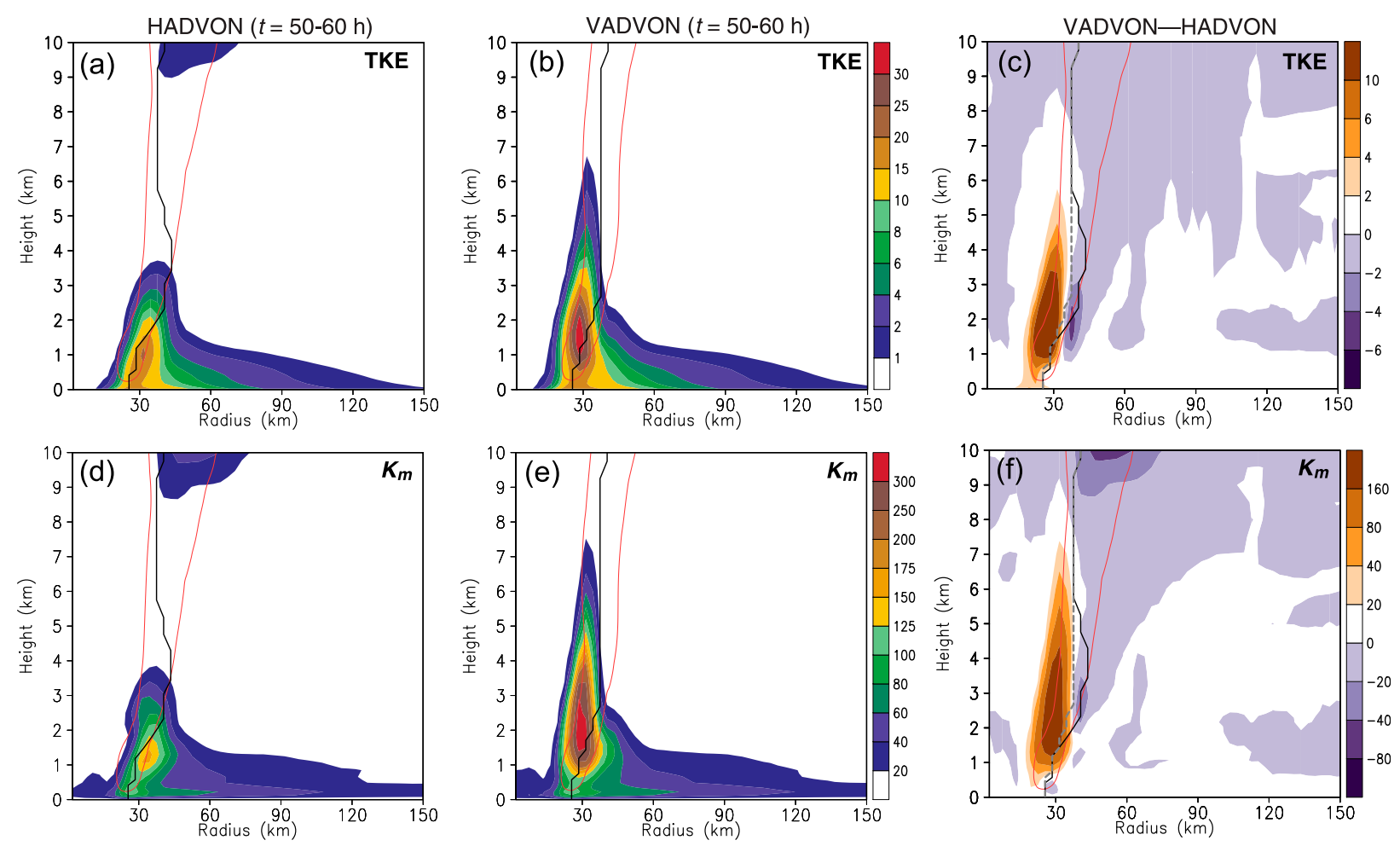

FIG. 13. (a),(b) Radius-height distribution of azimuthally averaged subgrid TKE (shading, $\mathrm{m}^{2} \mathrm{~s}^{-2}$ ) over $t=50-60 \mathrm{~h}$ for the HADVON and VADVON experiments, respectively. (c) The difference in the distribution of subgrid TKE between the two experiments (VADVON HADVON). (d)-(f) As in (a)-(c), but for $K_{m}$ (shading, $\mathrm{m}^{2} \mathrm{~s}^{-1}$ ). In each panel, the red contour denotes $w=1 \mathrm{~m} \mathrm{~s}^{-1}$ and the black line denotes the RMW. In (c) and (f), $w$ contours are from HADV; black and gray dashed lines denote the RMW from HADVON and VADVON experiments, respectively.

e.g., section 3 of Mellor and Yamada 1982; and p. 152 of Stull 1988). The horizontal diffusion in numerical weather prediction (NWP) models is typically parameterized separately based on the 2D Smagorinsky scheme (e.g., Zhang and Marks 2015). Contradicting these assumptions of 1D PBL schemes, observations in the eyewall and outer core of hurricanes indicate that the scale of energy-containing eddies in hurricane boundary layer is $>1 \mathrm{~km}$ (Zhang and Montgomery 2012), which is comparable with the horizontal grid spacings in NWP models. Thus, the assumption of horizontally inhomogeneity is invalid for the hurricane boundary layer, especially near the eyewall where the radial gradient of the thermodynamic and kinematic variables is substantial. A complete form of the shear production of TKE is (Mellor and Yamada 1982)

$$
\begin{aligned}
& -\left[\overline{u^{\prime} w^{\prime}} \frac{\partial u}{\partial z}+\overline{v^{\prime} w^{\prime}} \frac{\partial v}{\partial z}+\overline{u^{\prime} w^{\prime}} \frac{\partial w}{\partial x}+\overline{v^{\prime} w^{\prime}} \frac{\partial w}{\partial y}+\overline{u^{\prime} v^{\prime}}\left(\frac{\partial u}{\partial y}+\frac{\partial v}{\partial x}\right)\right. \\
& \left.+\overline{u^{\prime} u^{\prime}} \frac{\partial u}{\partial x}+\overline{v^{\prime} v^{\prime}} \frac{\partial v}{\partial y}+\overline{w^{\prime} w^{\prime}} \frac{\partial w}{\partial z}\right] .
\end{aligned}
$$

A comparison of Eqs. (4) and (7) indicates all but the first two terms in Eq. (7) are neglected in the shear production term of MYNN. In the strong updrafts in the eyewall, shear production terms due to the $\partial w / \partial x, \partial w / \partial y$, and $\partial w / \partial z$ probably should not be neglected. The shear production of TKE due to the horizontal wind shear [i.e., the fifth to seventh terms in Eq. (7)] may also play a role in the inflow/outflow layer near the eyewall. These factors are likely responsible for the difference in the TKE distribution between simulations and observations. These results also suggest that parameterizations of 3D turbulence (e.g., Zhang et al. 2018; Kosović et al. 2020) in high-order PBL schemes is physically more realistic for TC simulations, and should be investigated in future studies.

\section{Conclusions}

The tropical cyclone (TC) boundary layer is known for its high-wind conditions and horizontal inhomogeneity (e.g., Zhu 2008; Bryan et al. 2017). These characteristics challenge the typical design of one-dimensional (1D) PBL schemes that assume horizontal homogeneity, as the scale of energycontaining eddies is significantly smaller than NWP model horizontal grid spacings. Advection of subgrid turbulence kinetic energy (TKE) is thereby neglected in most NWP models with PBL schemes that predict subgrid TKE. This assumption could lead to errors in the TC simulations since the diagnosed turbulence quantities (including vertical viscosity $K_{m}$ ) depends crucially on the prognostic TKE.

To investigate the role of advection of parameterized TKE in TC simulations, this study performs a set of idealized numerical simulations using CM1 and the MYNN PBL scheme. We modified the near-surface TKE budget terms and mixing 

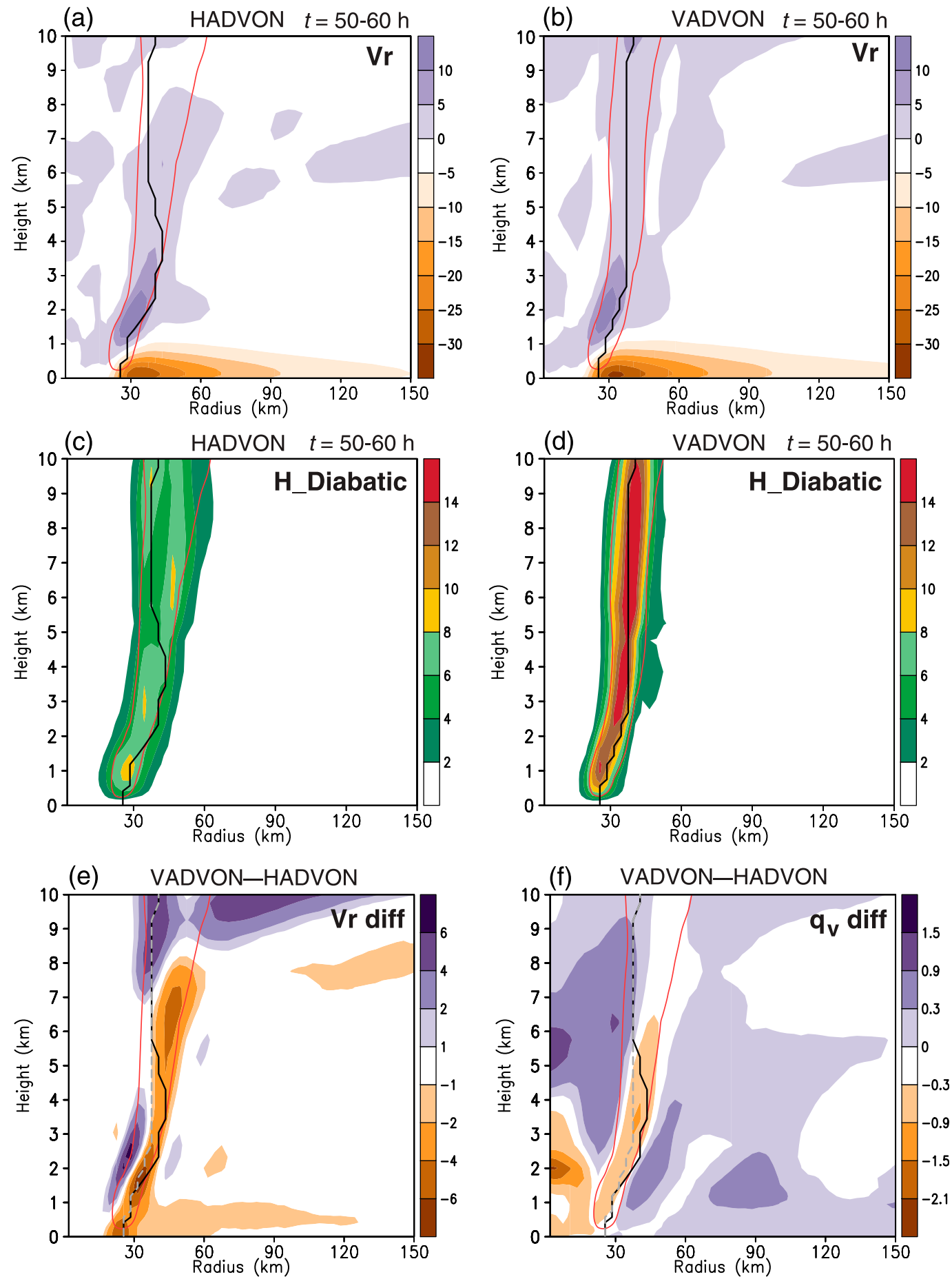

FIG. 14. (a),(b) Composite vertical structure of radial velocity (shading, $\mathrm{m} \mathrm{s}^{-1}$ ) over $t=50-60 \mathrm{~h}$ for HADVON and VADVON experiments, respectively. (c),(d) As in (a) and (b), but for microphysics diabatic heating $\left(10^{-3} \mathrm{~K} \mathrm{~s}^{-1}\right)$. The black line denotes the RMW and the red contour denotes $w=1 \mathrm{~m} \mathrm{~s}^{-1}$. The difference in the distribution of (e) radial winds and (f) specific humidity (shading, $\mathrm{g} \mathrm{kg}^{-1}$ ) between the two experiments (VADVON HADVON). In (e) and (f), $w$ contours are from HADVON. The black solid and gray dashed lines denote the RMW from HADVON and VADVON experiments, respectively. 

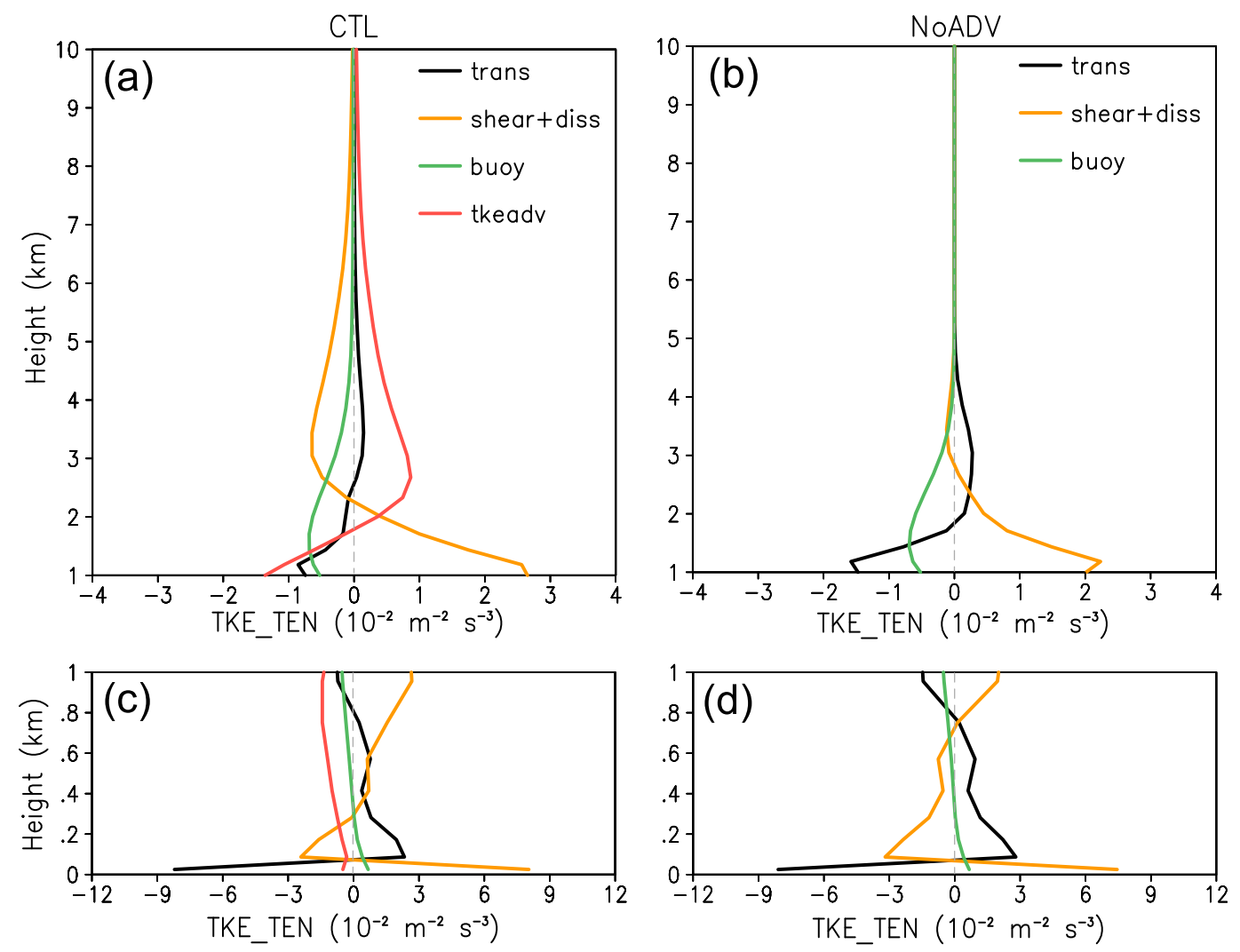

FIG. 15. Vertical profiles of subgrid TKE budget terms averaged within $r=15-45 \mathrm{~km}$ over $t=40-60 \mathrm{~h}$, showing the turbulent transport term (black), sum of shear production and dissipation (orange), buoyancy production (green), and advection of subgrid TKE (red) for (a) CTL and (b) NoADV from 1 to $10 \mathrm{~km}$ above the surface. (c),(d) As in (a) and (b), but for $0-1 \mathrm{~km}$ above the surface; note that the $x$-axis scale is different in (c) and (d). The vertical gray dashed line in each panel denotes the zero TKE tendency. The unit is $10^{-2} \mathrm{~m}^{-2} \mathrm{~s}^{-3}$.

length blending method in MYNN, which improves the wind profiles in the near-surface layer and in the mid- to upper boundary layer in single-column model simulations. Results from three-dimensional simulations demonstrate that with advection of subgrid TKE, the simulated TC is slightly stronger, the inner-core size is slightly smaller, and the radius of gale force wind (R34) is $\sim 5 \%$ smaller after approximately day 4.5 . This finding is robust regardless of the intensity/structure/innercore saturation fraction of the initial vortex, sea surface temperature, and microphysics scheme.

By further examining the two control simulations-i.e., CTL and NoADV - where the advection of subgrid TKE is on and off, respectively, we found that horizontal advection of subgrid TKE reduces TKE and $K_{m}$ in the inflow layer outside the radius of maximum wind (RMW), and produces the greatest differences near the RMW due to the larger radial gradient of subgrid TKE therein. Before the RMW and TC intensity diverge in the two control simulations, the NoADV TC has stronger maximum diabatic heating in the eyewall; however, the diabatic heating is stronger at smaller radii inside the RMW of the CTL TC, which is closely related to the enhanced boundary layer inflow near the RMW. The inflow angle within the annulus of $0.8-1.2 \times \mathrm{RMW}$ of the CTL TC is $2^{\circ}-3^{\circ}$ larger than that of NoADV TC. These differences are consistent with large absolute angular momentum near the surface being drawn to smaller radii, which facilitates the formation of a smaller inner core with stronger TC intensity in CTL.

A budget analysis of subgrid TKE further shows that the taller TKE "tower" in the eyewall in CTL is more consistent with the observations of Lorsolo et al. (2010) than in NoADV, and is attributed primarily to advection of subgrid TKE by eyewall updrafts. There are also differences in the MYNN length scale $L$ that contribute to higher TKE in the eyewall. In comparison, buoyancy production of TKE remains negative in the eyewall region except below the lowest $300 \mathrm{~m}$, which is predominantly attributable to the effects of stratification.

Interestingly, simulations that have only vertical or horizontal advection of TKE indicate that the differences between CTL and NoADV are mostly attributable to vertical advection of subgrid TKE, which acts to decrease TKE and $K_{m}$ in the lowest $\mathrm{km}$ of the eyewall. The inclusion of vertical advection of subgrid TKE also enhances the vertical mixing above the inflow layer and reduces the tilt of the outflow jet, and thereby eyewall convection is located at smaller radii inside the RMW. The enhanced vertical mixing above the inflow layer also transports more water vapor upward, which benefits the 


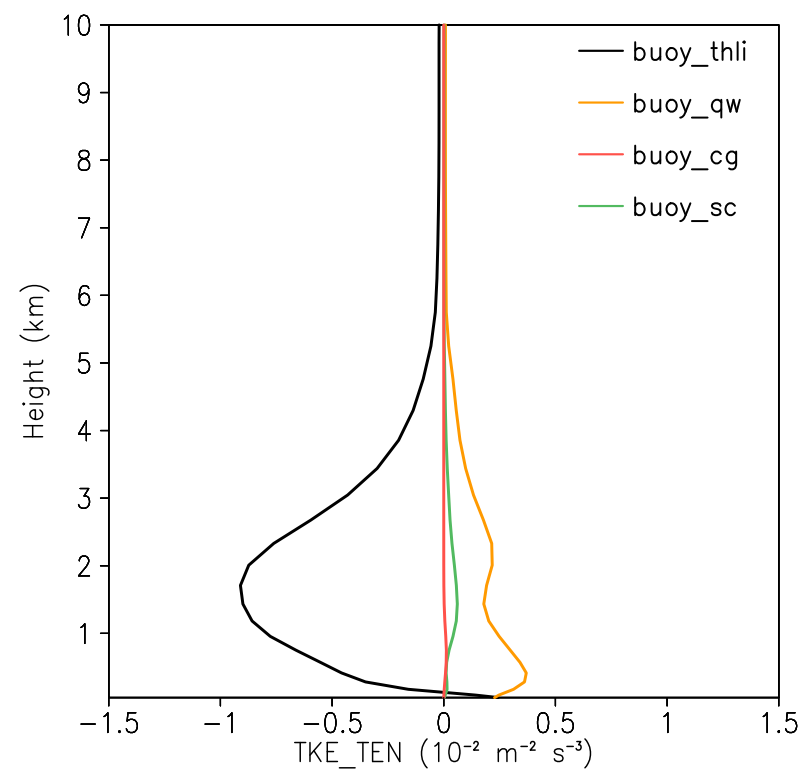

FIG. 16. Vertical profiles of subterms of buoyancy TKE production averaged within $r=15-45 \mathrm{~km}$ over $t=40-60 \mathrm{~h}$ for CTL, showing the buoyancy production due to stratification (black), vertical gradient of $q_{w}$ (orange), countergradient fluxes (red), and stratocumulus-cloud-top radiative cooling (green). The unit is $10^{-2} \mathrm{~m}^{-2} \mathrm{~s}^{-3}$.

development of convection inside the RMW. These factors together help account for the stronger diabatic heating at smaller radii inside the RMW, stronger TC intensity, as well as smaller RMW when the advection of subgrid TKE is turned on.

Results also suggest an inherent deficiency of 1D PBL schemes for simulating the inhomogeneous TC eyewall and thus we recommend developing and testing a $3 \mathrm{D}$ turbulence parameterization for TC simulations. Because these results are based on idealized simulations without the inclusion of environmental vertical wind shear or other synoptic-scale forcings, additional tests of actual TCs are encouraged for future work. Also, this study focuses on the impact of advection of subgrid TKE on TC intensity and size, and does not address its impact on the asymmetry structures like in the eyewall, which will be left for future work.

Acknowledgments. We would like to acknowledge highperformance computing support from Cheyenne (https://doi.org/ 10.5065/D6RX99HX) provided by NCAR's Computational and Information Systems Laboratory, sponsored by the National Science Foundation. We appreciate Dr. Jun Zhang for generously sharing the inflow angle data. We also acknowledge Dr. Andy Hazelton for his helpful suggestions to improve this manuscript. The first author, Xiaomin Chen, is supported by an NRC Research Associateship award. George Bryan is supported by the National Center for Atmospheric Research, which is a major facility sponsored by the National Science Foundation under Cooperative Agreement 1852977, and by Office of Naval Research Grant N00014-20-1-2071.

\section{APPENDIX}

\section{Decomposition of Buoyancy TKE Production Term}

In MYNN, a partial-condensation scheme is used for the condensation process following Sommeria and Deardorff (1977). The buoyancy flux $\overline{w^{\prime} \theta_{v}^{\prime}}$ is written in the form of liquid-ice water potential temperature $\theta_{l i}$ and total water content $q_{w}$ [Eq. (3) in Olson et al. 2019], with the sign corrected:

$$
\overline{w^{\prime} \theta_{v}^{\prime}}=\beta_{\theta} \overline{w^{\prime} \theta_{l i}^{\prime}}+\beta_{q} \overline{w^{\prime} q_{w}^{\prime}}+A\left(\frac{\theta_{v}}{g}\right) \frac{w_{l}^{3}}{h}(h-z)\left(1-\frac{h-z}{h}\right)^{3},
$$

where $\beta_{\theta}$ and $\beta_{q}$ are functions determined by condensation processes, $A$ is entrainment efficiency, $h$ denotes PBL height. The convective velocity scale $w_{l}=\left[g / \theta_{v}\left(w^{\prime} \theta^{\prime}\right)_{h} h\right]^{1 / 3}$, where $\left(w^{\prime} \theta^{\prime}\right)_{h}$ is the radiative flux due to stratocumulus-cloud-top cooling at the PBL height. Following Nakanishi and Niino (2009),

$$
\begin{aligned}
& \overline{w^{\prime} \theta_{l i}^{\prime}}=-L q\left(S_{H 2.5} \frac{\partial \theta_{l i}}{\partial z}+\Gamma_{\theta}\right), \\
& \overline{w^{\prime} q_{w}^{\prime}}=-L q\left(S_{H 2.5} \frac{\partial q_{w}}{\partial z}+\Gamma_{q}\right),
\end{aligned}
$$

where $S_{H 2.5}$ is the stability function for a level-2.5 model for heat and moisture, and $\Gamma_{\theta}$ and $\Gamma_{q}$ represent effects of countergradient diffusion. Thus, buoyancy production of TKE can be rewritten as

$$
\begin{aligned}
\frac{g}{\theta_{v}} \overline{w^{\prime} \theta_{v}^{\prime}}= & -\frac{g \beta_{\theta} L q S_{H 2.5}}{\theta_{v}} \frac{\partial \theta_{l i}}{\partial z}-\frac{g \beta_{q} L q S_{H 2.5}}{\theta_{v}} \frac{\partial q_{w}}{\partial z} \\
& -\frac{g L q}{\theta_{v}}\left(\beta_{\theta} \Gamma_{\theta}+\beta_{q} \Gamma_{q}\right)+A \frac{w_{l}^{3}}{h}(h-z)\left(1-\frac{h-z}{h}\right)^{3},
\end{aligned}
$$

where terms on the rhs of (A3) denote buoyancy production due to stratification, vertical gradient of $q_{w}$, countergradient fluxes, and stratocumulus-cloud-top radiative cooling, respectively.

\section{REFERENCES}

Bell, M. M., M. T. Montgomery, and K. A. Emanuel, 2012: Air-sea enthalpy and momentum exchange at major hurricane wind speeds observed during CBLAST. J. Atmos. Sci., 69, 31973222, https://doi.org/10.1175/JAS-D-11-0276.1.

Bougeault, P., and P. Lacarrere, 1989: Parameterization of orography-induced turbulence in a mesobeta-scale model. Mon. Wea. Rev., 117, 1872-1890, https://doi.org/10.1175/ 1520-0493(1989)117<1872:POOITI >2.0.CO;2.

Braun, S. A., and W.-K. Tao, 2000: Sensitivity of high-resolution simulations of Hurricane Bob (1991) to planetary boundary layer parameterizations. Mon. Wea. Rev., 128, 3941-3961, https:// doi.org/10.1175/1520-0493(2000)129<3941:SOHRSO>2.0.CO;2.

Brown, B. R., M. M. Bell, and A. J. Frambach, 2016: Validation of simulated hurricane drop size distributions using polarimetric radar. Geophys. Res. Lett., 43, 910-917, https://doi.org/10.1002/ 2015 GL067278.

Bryan, G. H., 2012: Effects of surface exchange coefficients and turbulence length scales on the intensity and structure of 
numerically simulated hurricanes. Mon. Wea. Rev., 140, 11251143, https://doi.org/10.1175/MWR-D-11-00231.1.

—_, and J. M. Fritsch, 2002: A benchmark simulation for moist nonhydrostatic numerical models. Mon. Wea. Rev., 130, 2917-2928, https://doi.org/10.1175/1520-0493(2002) $130<2917$ :ABSFMN $>2.0$. CO;2.

—, R. P. Worsnop, J. K. Lundquist, and J. A. Zhang, 2017: A simple method for simulating wind profiles in the boundary layer of tropical cyclones. Bound.-Layer Meteor., 162, 475502, https://doi.org/10.1007/s10546-016-0207-0.

Bu, Y. P., R. G. Fovell, and K. L. Corbosiero, 2017: The influences of boundary layer mixing and cloud-radiative forcing on tropical cyclone size. J. Atmos. Sci., 74, 1273-1292, https:// doi.org/10.1175/JAS-D-16-0231.1.

Chen, X., J. A. Zhang, and F. D. Marks, 2019: A thermodynamic pathway leading to rapid intensification of tropical cyclones in shear. Geophys. Res. Lett., 46, 9241-9251, https://doi.org/ 10.1029/2019GL083667.

_ , G. H. Bryan, J. A. Zhang, J. J. Cione, and F. D. Marks, 2021a: A framework for simulating the tropical-cyclone boundary layer using large-eddy simulation and its use in evaluating PBL parameterizations. J. Atmos. Sci., 78, 3559-3574, https:// doi.org/10.1175/JAS-D-20-0227.1.

_- M. Xue, B. Zhou, J. Fang, J. A. Zhang, and F. D. Marks, 2021b: Effect of scale-aware planetary boundary layer schemes on tropical cyclone intensification and structural changes in the gray zone. Mon. Wea. Rev., 149, 2079-2095, https://doi.org/ 10.1175/MWR-D-20-0297.1.

Cione, J. J., and Coauthors, 2020: Eye of the storm: Observing hurricanes with a small unmanned aircraft system. Bull. Amer. Meteor. Soc., 101, E186-E205, https://doi.org/10.1175/BAMSD-19-0169.1.

Dunion, J. P., 2011: Rewriting the climatology of the tropical North Atlantic and Caribbean Sea atmosphere. J. Climate, 24, 893908, https://doi.org/10.1175/2010JCLI3496.1.

Foster, R. C., 2009: Boundary-layer similarity under an axisymmetric, gradient wind vortex. Bound.-Layer Meteor., 131, 321344, https://doi.org/10.1007/s10546-009-9379-1.

French, J. R., W. M. Drennan, J. A. Zhang, and P. G. Black, 2007: Turbulent fluxes in the hurricane boundary layer. Part I: Momentum flux. J. Atmos. Sci., 64, 1089-1102, https://doi.org/ 10.1175/JAS3887.1.

Gopalakrishnan, S. G., F. Marks, J. A. Zhang, X. Zhang, J.-W. Bao, and V. Tallapragada, 2013: A study of the impacts of vertical diffusion on the structure and intensity of the tropical cyclones using the high-resolution HWRF system. J. Atmos. Sci., 70, 524-541, https://doi.org/10.1175/JAS-D-11-0340.1.

Harris, L., and Coauthors, 2020: GFDL SHiELD: A unified system for weather-to-seasonal prediction. J. Adv. Model. Earth Syst., 12, e2020MS002223, https://doi.org/10.1029/2020MS002223.

Iacono, M. J., J. S. Delamere, E. J. Mlawer, M. W. Shephard, S. A. Clough, and W. D. Collins, 2008: Radiative forcing by longlived greenhouse gases: Calculations with the AER radiative transfer models. J. Geophys. Res., 113, D13103, https://doi.org/ 10.1029/2008JD009944.

Kepert, J. D., 2012: Choosing a boundary layer parameterization for tropical cyclone modeling. Mon. Wea. Rev., 140, 14271445, https://doi.org/10.1175/MWR-D-11-00217.1.

Kilroy, G., R. K. Smith, and M. T. Montgomery, 2017: A unified view of tropical cyclogenesis and intensification. Quart. J. Roy. Meteor. Soc., 143, 450-462, https://doi.org/10.1002/qj.2934.

Kosović, B., P. Jimenez Munoz, T. W. Juliano, A. Martilli, M. Eghdami, A. P. Barros, and S. E. Haupt, 2020: Three-dimensional planetary boundary layer parameterization for high-resolution mesoscale simulations. J. Phys. Conf. Ser., 1452, 012080, https://doi.org/ 10.1088/1742-6596/1452/1/012080.

Kurihara, Y., and R. E. Tuleya, 1974: Structure of a tropical cyclone developed in a three-dimensional numerical simulation model. J. Atmos. Sci., 31, 893-919, https://doi.org/10.1175/ 1520-0469(1974)031<0893:SOATCD >2.0.CO;2.

Lorsolo, S., J. A. Zhang, F. Marks, and J. Gamache, 2010: Estimation and mapping of hurricane turbulent energy using airborne Doppler measurements. Mon. Wea. Rev., 138, 36563670, https://doi.org/10.1175/2010MWR3183.1.

Mason, P. J., and D. J. Thomson, 1992: Stochastic backscatter in large-eddy simulations of boundary layers. J. Fluid Mech., 242, 51-78, https://doi.org/10.1017/S0022112092002271.

Mellor, G. L., and T. Yamada, 1974: A hierarchy of turbulence closure models for planetary boundary layers. J. Atmos. Sci., 31, 1791-1806, https://doi.org/10.1175/1520-0469(1974) 031<1791:AHOTCM>2.0.CO;2.

- , and - 1982: Development of a turbulence closure model for geophysical fluid problems. Rev. Geophys., 20, 851-875, https://doi.org/10.1029/RG020i004p00851.

Ming, J., J. A. Zhang, R. F. Rogers, F. D. Marks, Y. Wang, and N. Cai, 2014: Multiplatform observations of boundary layer structure in the outer rainbands of landfalling typhoons. J. Geophys. Res. Atmos., 119, 7799-7814, https://doi.org/ 10.1002/2014JD021637.

Nakanishi, M., and H. Niino, 2004: An improved Mellor-Yamada level-3 model with condensation physics: Its design and verification. Bound.-Layer Meteor., 112, 1-31, https://doi.org/ 10.1023/B:BOUN.0000020164.04146.98.

$\longrightarrow$, and - 2009: Development of an improved turbulence closure model for the atmospheric boundary layer. J. Meteor. Soc. Japan, 87, 895-912, https://doi.org/10.2151/jmsj.87.895.

Nolan, D. S., D. P. Stern, and J. A. Zhang, 2009: Evaluation of planetary boundary layer parameterizations in tropical cyclones by comparison of in situ observations and high-resolution simulations of Hurricane Isabel (2003). Part II: Inner-core boundary layer and eyewall structure. Mon. Wea. Rev., 137, 3675-3698, https://doi.org/10.1175/2009MWR2786.1.

Olson, J. B., J. S. Kenyon, W. A. Angevine, J. M. Brown, M. Pagowski, and K. Sušelj, 2019: A description of the MYNN-EDMF scheme and the coupling to other components in WRF-ARW. NOAA Tech. Memo. OAR GSD-61, 37 pp., https://doi.org/10.25923/n9wm-be49.

Peng, K., R. Rotunno, G. H. Bryan, and J. Fang, 2019: Evolution of an axisymmetric tropical cyclone before reaching slantwise moist neutrality. J. Atmos. Sci., 76, 1865-1884, https://doi.org/ 10.1175/JAS-D-18-0264.1.

Powell, M. D., P. J. Vickery, and T. A. Reinhold, 2003: Reduced drag coefficient for high wind speeds in tropical cyclones. Nature, 422, 279-283, https://doi.org/10.1038/nature01481.

Rappin, E. D., D. S. Nolan, and K. A. Emanuel, 2010: Thermodynamic control of tropical cyclogenesis in environments of radiative-convective equilibrium with shear. Quart. J. Roy. Meteor. Soc., 136, 1954-1971, https://doi.org/ 10.1002/qj.706.

Richter, D. H., R. Bohac, and D. P. Stern, 2016: An assessment of the flux profile method for determining air-sea momentum and enthalpy fluxes from dropsonde data in tropical cyclones. J. Atmos. Sci., 73, 2665-2682, https://doi.org/10.1175/JAS-D15-0331.1.

— C. Wainwright, D. P. Stern, G. H. Bryan, and D. Chavas, 2021: Potential low bias in high-wind drag coefficient inferred 
from dropsonde data in hurricanes. J. Atmos. Sci., 78, 23392352, https://doi.org/10.1175/JAS-D-20-0390.1.

Rotunno, R., and G. H. Bryan, 2012: Effects of parameterized diffusion on simulated hurricanes. J. Atmos. Sci., 69, 2284 2299, https://doi.org/10.1175/JAS-D-11-0204.1.

Skamarock, W. C., and Coauthors, 2008: A description of the Advanced Research WRF version 3. NCAR Tech Note NCAR/ TN-475+STR, 113 pp., https://doi.org/10.5065/D68S4MVH.

Smith, R. K., and G. L. Thomsen, 2010: Dependence of tropicalcyclone intensification on the boundary-layer representation in a numerical model. Quart. J. Roy. Meteor. Soc., 136, 16711685, https://doi.org/10.1002/qj.687.

— , and M. T. Montgomery, 2016: The efficiency of diabatic heating and tropical cyclone intensification. Quart. J. Roy. Meteor. Soc., 142, 2081-2086, https://doi.org/10.1002/qj.2804.

Sommeria, G., and J. W. Deardorff, 1977: Subgrid-scale condensation in models of nonprecipitating clouds. J. Atmos. Sci., 34, 344-355, https://doi.org/10.1175/1520-0469(1977) $034<0344:$ SSCIMO $>2.0$. CO 2 .

Stull, R. B., 1988: An Introduction to Boundary Layer Meteorology. Kluwer Academic, 666 pp.

Thompson, G., P. R. Field, R. M. Rasmussen, and W. D. Hall, 2008: Explicit forecasts of winter precipitation using an improved bulk microphysics scheme. Part II: Implementation of a new snow parameterization. Mon. Wea. Rev., 136, 5095-5115, https://doi.org/10.1175/2008MWR2387.1.

Wu, D., F. Zhang, X. Chen, A. Ryzhkov, K. Zhao, M. Kumjian, X. Chen, and P. Chan, 2021: Evaluation of microphysics schemes in tropical cyclones using polarimetric radar observations: Convective precipitation in an outer rainband. Mon. Wea. Rev., 149, 1055-1068, https://doi.org/10.1175/MWR-D19-0378.1.
Zhang, J. A., and M. T. Montgomery, 2012: Observational estimates of the horizontal eddy diffusivity and mixing length in the low-level region of intense hurricanes. J. Atmos. Sci., 69 , 1306-1316, https://doi.org/10.1175/JAS-D-11-0180.1.

— , and E. W. Uhlhorn, 2012: Hurricane sea surface inflow angle and an observation-based parametric model. Mon. Wea. Rev., 140, 3587-3605, https://doi.org/10.1175/MWR-D-11-00339.1.

_ , and F. D. Marks, 2015: Effects of horizontal diffusion on tropical cyclone intensity change and structure in idealized three-dimensional numerical simulations. Mon. Wea. Rev., 143, 3981-3995, https://doi.org/10.1175/MWR-D-14-00341.1.

——, — M. T. Montgomery, and S. Lorsolo, 2011: An estimation of turbulent characteristics in the low-level region of intense Hurricanes Allen (1980) and Hugo (1989). Mon. Wea. Rev., 139, 1447-1462, https://doi.org/10.1175/ 2010MWR3435.1.

- D. S. Nolan, R. F. Rogers, and V. Tallapragada, 2015: Evaluating the impact of improvements in the boundary layer parameterization on hurricane intensity and structure forecasts in HWRF. Mon. Wea. Rev., 143, 3136-3155, https:// doi.org/10.1175/MWR-D-14-00339.1.

Zhang, X., J.-W. Bao, B. Chen, and E. D. Grell, 2018: A threedimensional scale-adaptive turbulent kinetic energy scheme in the WRF-ARW Model. Mon. Wea. Rev., 146, 2023-2045, https://doi.org/10.1175/MWR-D-17-0356.1.

Zhu, P., 2008: Simulation and parameterization of the turbulent transport in the hurricane boundary layer by large eddies. J. Geophys. Res., 113, D17104, https://doi.org/ 10.1029/2007JD009643.

— , and Coauthors, 2019: Role of eyewall and rainband eddy forcing in tropical cyclone intensification. Atmos. Chem. Phys., 19, 14 289-14 310, https://doi.org/10.5194/acp-19-14289-2019. 